\title{
Chitosan and Graphene Oxide-based Nanocomposites for Water Purification and Medical Applications: A Review
}

\begin{abstract}
Vinita Khandegar, ${ }^{a}$ Perminder Jit Kaur, ${ }^{\mathrm{b}, *}$ and Pratibha Chanana ${ }^{\mathrm{a}}$
Chitosan (CS) is a natural polysaccharide isolated from insects, molluscs, and fungi. The specific properties of chitosan can be enhanced using physicochemical processes. The composites prepared using CS and graphene oxide (GO) contain active functional groups such as epoxide, carboxyl, and hydroxyl, which possess excellent biocompatibility, high adsorption capacity, and biodegradability. Their low cost and ease of scaleup make them employable for multiple applications in water-treatment plants, electronics, solar cells, and pharmaceuticals. This review provides an overview of sources, types, and properties of chitin, chitosan, and graphene oxide. The use of these composites for the preparation of antimicrobial drugs has been discussed here. The article also explores the applicability of such composites for removal of heavy metals (lead, copper, chromium, cobalt, mercury, etc.), dyes (methylene blue and other reactive dyes), and organic and inorganic contaminants (ofloxacin, naphthanol, phenol, and oil, etc.). The article highlights various knowledge gaps in the field and the scope of future work.
\end{abstract}

Keywords: Chitosan; Graphene oxide; Nanocomposite; Water purification; Medical applications

Contact information: a: University School of Chemical Technology, Guru Gobind Singh Indraprastha University, New Delhi, 110078, India; b: Centre for Policy Research, Department of Science and Technology, New Delhi, 110016, India; *Corresponding author: perminder.dua@gmail.com

\section{INTRODUCTION}

Polymer-based nanocomposites have applications in various fields such as wastewater treatment, electronics, energy, pharmaceuticals, and medicine. Low cost, high recyclability, biocompatibility, ease of degradability, and scalability make bio-based, commonly available, natural polymers such as chitosan (CS) materials of choice for multiple fields ranging from wastewater treatment to medicinal applications (Dutta et al. 2004; Cheung et al. 2015; Palza 2015). Their high affinity for metals, organic and inorganic particles coupled with the higher surface area makes them promising materials for the removal of contaminants from wastewater (Chen et al. 2013; Schwarz et al. 2016; Singh et al. 2019; Suri 2020; Suri et al. 2021; Upadhyay et al. 2021). In combination with graphene oxide (GO) and inorganic nanoparticles such as $\mathrm{ZnO}, \mathrm{Fe}_{3} \mathrm{O}_{4}, \mathrm{GO}$, and $\mathrm{TiO}_{2}$, it is possible to introduce additional functional groups that can increase their chelation capacity, improve the surface area and active sites, and assist in further modification of their properties (Kyzas and Bikiaris 2015; Morsy 2015; Salam 2017; ZabihiSahebi et al. 2019).

The presence of heavy metals in soil and water is a significant threat to the ecosystem. Heavy metals, dyes, and inorganic pollutants are widespread through various sources and taken up by plants in the environment. As a result, they enter into the food chain and are ingested by humans and animals. Consistent efforts are being made to 
effectively remove contaminated water and soil samples (Chauhan et al. 2020). Various heavy metals like copper, chromium, and mercury are removed from contaminated samples using composting, landfarming, coagulation, flocculation, membrane separation, and adsorption processes (Kaur et al. 2020). Attempts have been made in the literature to develop green adsorbents for wastewater treatment.

$\mathrm{Cs}$ and $\mathrm{GO}$ are promising materials with unique properties such as biocompatibility, safety, and antimicrobial capacity. They are also proven to be effective as drug delivery agents. Attempts on forming nanocomposites made from natural materials such as CS and GO in various ways have yielded properties even better than individual CS or GO used alone (Ates et al. 2020). Thus, the present literature study covers the essential aspects of $\mathrm{CS}$ and GO-based nanocomposites and their applicability in the specified areas. It explores the sources, types, and properties of CS and GO. The applications of modified CS-GObased composites for removing heavy metals, dyes, and pollutants from wastewater are reviewed. An overview of its antimicrobial properties and potential as a medium for drug delivery is also presented. This information can serve as a reference document for technologists and scientists to research and develop new systems based on Cs-GO nanocomposites (Ahmad et al. 2017).

\section{ORIGIN AND SOURCES OF CHITIN AND CHITOSAN}

The word chitin is derived from the Greek word "Chiton", meaning covering or envelope. It was discovered as a new polysaccharide and reported for the first time in 1811 by French professor Henri Braconnot as fungine while researching edible mushrooms. Later, in 1823, Antoine Odier named it chitine because of its unique presence in insects' cuticles (Crini 2019). Later, its structure was determined by Albert Hofman (Hofmann 1979). In 1859, Charles Rouget described deacetylation of chitin to obtain a modified form of chitin, which was later termed chitosan by Hoppe-Seyler in 1894 (Crini 2019). The polysaccharides chitin and chitosan are made up of amino sugars D-glucosamine and $\mathrm{N}$ acetyl-D-glucosamine. The ratio of amino sugars D-glucosamine and $N$-acetyl-Dglucosamine indicates whether the polysaccharide is considered chitin or chitosan (Brigham 2017). Chitosan is a linear cationic copolymer consisting of alternating units of $\mathrm{N}$-acetyl-glucosamine $(20 \%)$ and D-glucosamine ( 80\%) obtained by deacetylation of chitin, whereas chitin is a linear polymer composed of repeated units of $\beta$-1,4-linked $N$ acetylglucosamine (50\%) (Philibert et al. 2017; Hahn et al. 2020b). Both polymers have exclusive properties and find applications in various fields (Cheung et al. 2015; Younes and Rinaudo 2015). Chitin consists of huge crystalline nitrogen-containing polysaccharides with an estimated production of about $10^{11}$ to $10^{14}$ tons per annum (Bastiaens et al. 2019). Due to versatility and accessibility, chitin is the second most abundant polysaccharide after cellulose and hemicellulose.

The primary sources of chitin and chitosan are shown in Fig. 1. The most common source of chitin is shellfish and other aquatic invertebrates. These species are found in considerable quantities in the fish processing industry (Yadav et al. 2019). Chitin is located in the exoskeleton of sea animals such as annelids, molluscs, coelenterate, crustaceans (crabs, shrimps, and lobsters), and insects such as honey bee, silkworms, scorpions, spiders, ants, beetles, and cockroaches as supporting tissues of organisms (Kaur and Dhillon 2014). The content of chitin is highest in shrimp cuticle and squid pen waste, ranging from 15 to $40 \%$ as compared to other crustacean waste since shrimps have a thinner shell wall than 
lobsters and crabs (Tharanathan and Kittur 2003; Wang et al. 2020; Tan et al. 2020; Khayrova et al. 2021; Kou et al. 2021). While insects are a viable substitute source for chitin, being an abundant species globally, a lower quantity of chitin is extracted from fungi such as F. fomentarius and L. vellereus (Bastiaens et al. 2019, Sagheer et al. 2009). A significant part of the head and shell waste is obtained only from shrimp (about 60\%). At the same time, the cuticle can contain up to $80 \%$ chitin (Pal et al. 2014). The amount of chitin depends on the type of species, body part, season, and growth rate.

In contrast, chitosan is a partially deacetylated copied form of chitin (Letourneau et al. 1976). Chitosan content of 1 to $10 \%$ on dry biomass base has been found, with a reported degree of deacetylation of 83 to $94 \%$. Chitosan is produced synthetically by converting chitin in the presence of a deacetylase enzyme (Dhillon et al. 2013).

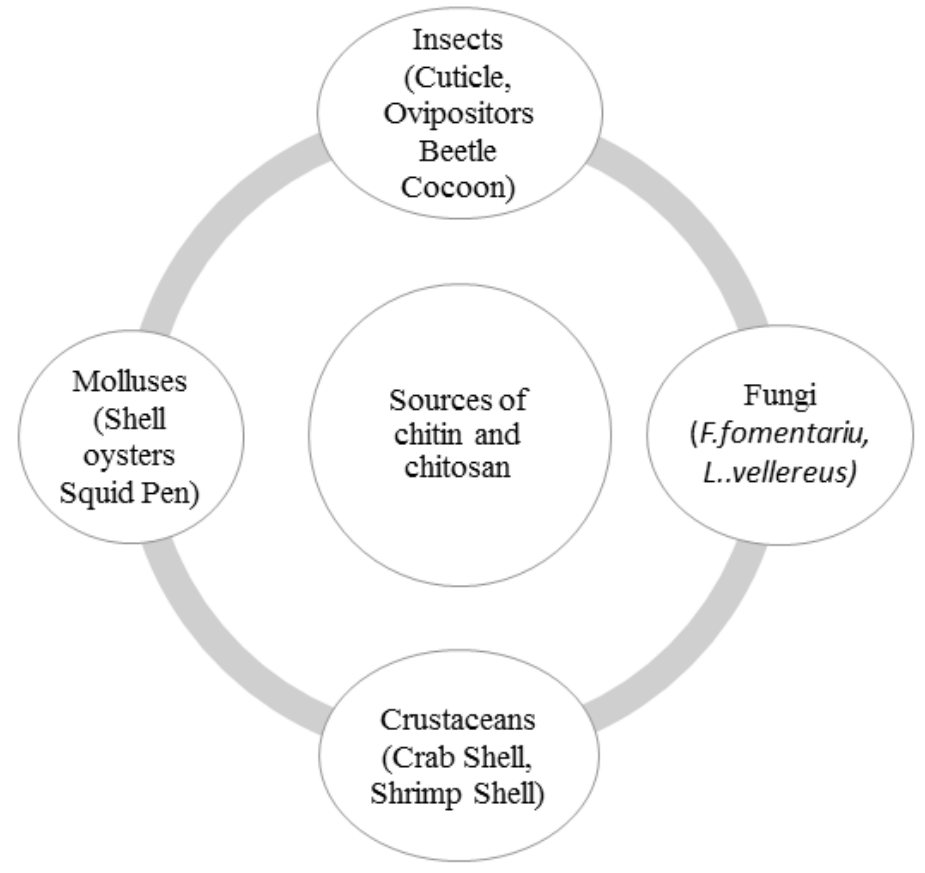

Fig. 1. Sources of chitin and chitosan

In addition to fungi, bacteria can be used for the production of chitosan using enzymatic deacetylation. Kaur and Dhillon (2014) isolated chitosan from soil bacteria (Bacillus sp. and Serritia sp.) through chitin's deacetylation. However, the efficiency of this process is affected by the insolubility and degradation of chitin (Aranaz et al. 2009). In addition, Kaur et al. (2012) suggested that the fast-growing bacteria or the isolated enzymes can be used for natural chitosan production. Over 10 billion tons of chitin are produced annually from the seafood processing industry (Casadidio et al. 2019). Chitin and chitosan are now extracted commercially in India, Japan, Poland, Australia, and the US. In the future, chitin's production rate will increase significantly due to increased waste generation of insects, exuviae, and exoskeletons. More research is required for surplus sources and utility of chitin/chitosan in the near term (Dutta et al. 2004).

Three types of crystal-like forms of chitin $\alpha, \beta$, and $\gamma$ (mixer of $\alpha$ and $\beta$ chitin) are found in nature (Aam et al. 2010). Different types of chitin allomorphs are shown in Fig. 2. Of these, $\alpha$ chitin is typically isolated from the shells and the exoskeleton of crustaceans, insect cuticles, shrimps, crab, and lobsters (Kaur and Dhillon 2014; Yadav et al. 2019). In 
$\alpha$ chitin, polysaccharide chains are organized in an antiparallel direction, allowing maximum bonding. Hence, $\alpha$ chitin is highly stable, having a high degree of crystallinity (80\%). $\beta$ chitin is usually found in squid pens, aphrodite chaetae, seaweeds, protozoa (Sagheer et al. 2009; Hajji et al. 2014). Here, polysaccharide chains are organized in parallel, with a crystallinity index of $70 \%$. The target distance between the adjacent polymer chains makes it more reactive and soluble in solvents (Yadav et al. 2019). The $\gamma$ chitin exists mainly in fungi and yeast. It is recognized by two parallel and one antiparallel sheet arrangement.

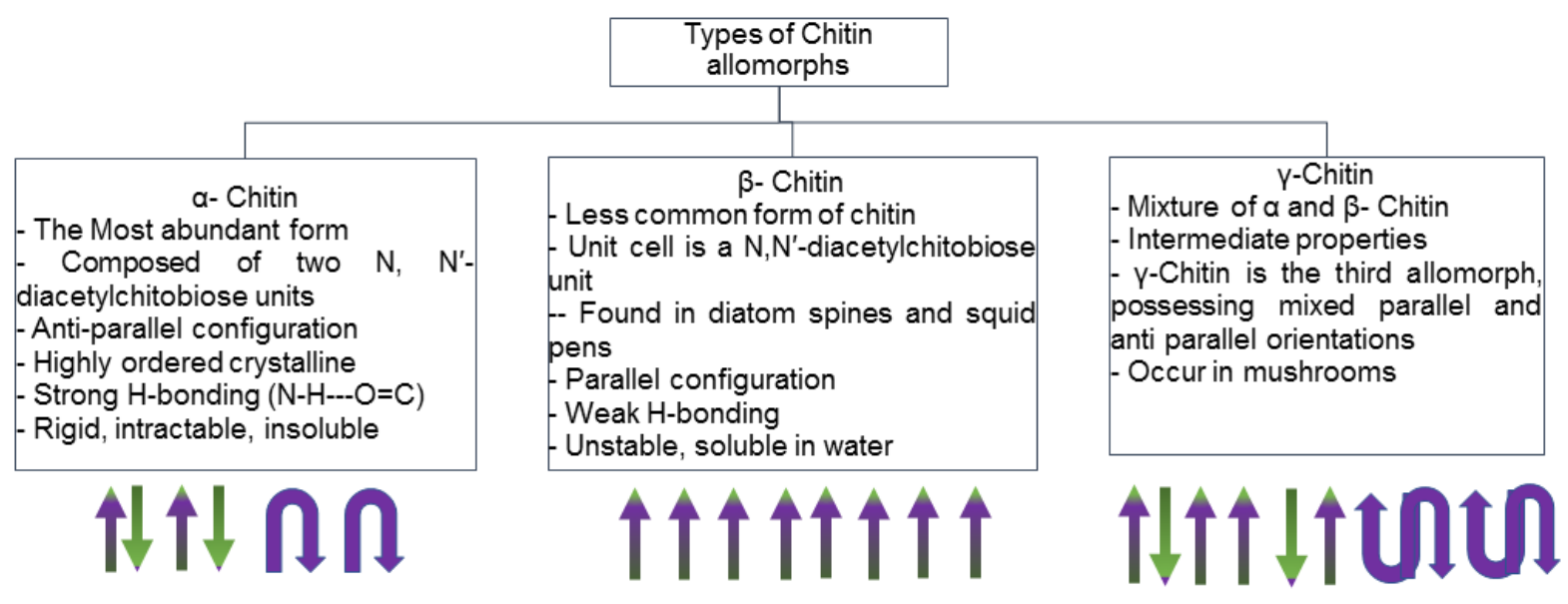

Fig. 2. Different types of Chitin Allomorphs

\section{PROPERTIES OF CHITIN AND CHITOSAN}

CS is more versatile than chitin due to amino groups at the C-2 positions (Dutta et al. 2004). Modification of chitin and CS help in the increasing of its solubility and versatility (Ishihara et al. 2012). Both chitin and CS can form films, chelate with metals, and moderate water permeability (Dutta et al. 2004). Due to low toxicity and digestibility, they can be used as food additives. Also, they are shown to be helpful to lower cholesterol in human blood (Knoor 1983). Both prevent the invasion of pathogens. However, chitosan is known to exhibit better properties and thus applicability than chitin. Chitin is a white, rigid, inelastic, nitrogenous polysaccharide (5 to $7 \%$ nitrogen). Being hydrophobic, it is insoluble in water and organic solvents. Due to its one reactive amine and two hydroxyl groups, chitosan has higher solubility, hydrophilic character, and adsorption capacity than chitin. CS is also soluble in aqueous solutions of acids. Solubility in aqueous solution gets further enhanced by $\mathrm{N}$-alkylidinations and $\mathrm{N}$-acylation (Muzzarelli 1997). It has an extensive semicrystalline structure. It has low immunogenicity and binds to mammalian and microbial cell aggregates (Dutta et al. 2004; Cheung et al. 2015). CS also displays mucoadhesive film-forming and chelating activity (Patra et al. 2018). The $\mathrm{pH}$ sensitivity and high biological compatibility of chitosan motivate researchers to explore its application in drug delivery systems, especially for cancer treatment (Dutta et al. 2004; Philibert et al. 2017; Yassue-Cordeiro et al. 2018; Ramachandran et al. 2019). Due to its long shelf-life and ability to form semipermeable, rigid, permanent and impermeable films, it can be used to wrap food products (Muzzarelli et al. 1986). CS is effective to remove endotoxins found in proteins as contaminants. Endotoxins are $\mathrm{pH}$ and heat stable and are not easily destroyable using normal sterilising conditions. CS can interact with endotoxins and help 
in downstream protein purification processes (Wang et al. 2013a).

$\mathrm{CS}$ is biocompatible, non-toxic, biodegradable, and has broad-spectrum antimicrobial activities (Jiang et al. 2014). The antifungal activity of CS is higher than chitin (Limam et al. 2011). CS can promote bone formation because it can be shaped into structures and geometries suitable for cell in-growth and post-growth conditions (Figueiredo et al. 2015). With unique biological activities, including analgesic, antitumor, haemostatic, and antioxidant properties, CS finds application in the biomedical field (Brigham 2017; Casadidio et al. 2019).

\section{METHODS OF EXTRACTION OF CS}

The chitosan family consists of different D-N-deacetylated forms of chitin, and its properties are highly dependent on the degree of deacetylation and its molecular weight (Younes and Rinaudo 2015; Philibert et al. 2017). CS is extracted from chitin through demineralization, deproteinization, deacetylation, and decolourization using chemical or biological processes such as enzymatic treatment or fermentation. It can be synthesized through nitrogen and oxygen substitution, copolymerization, and numerous other methods (Wang et al. 2016, 2020).

The difference in alkali solution concentration, reaction time, temperature, chitin/alkali solution ratio, CS with different degrees of deacetylation can be obtained. The degree of acetylation represents the percentage of $\mathrm{N}$-acetyl-d-glucosamine units to the total number of units. Hence for CS, the percentage degree of acetylation is below 50. Acetyl groups are removed arbitrarily, and a de-polymerization reaction occurs, which is indicated by changes in the molecular weight of CS. Various methods for the extraction of chitin and CS have been reported, although no standard practice has been implemented. However, demineralization and deproteinization are mostly chosen either using chemicals or biological agents. Few studies for extraction of chitin and chitosan using chemical and biological extraction are discussed below.

Different researchers have investigated various chemicals and solutions to extract CS and chitin. Deproteinization is a fundamental step used to extract protein, while demineralization is an acidic step used to remove the inorganic calcium carbonate (Khanafari et al. 2008; Tan et al. 2020). In the demineralization process, hydrochloric acid, nitric acid, sulfuric acid, acetic acid, and formic acid are used. In contrast, the alkaline method for deproteinization is commonly used for protein extraction (Brine and Austin 1981). Figure 3 explains the general procedure used for the extraction of chitin from crab and shrimp waste. 


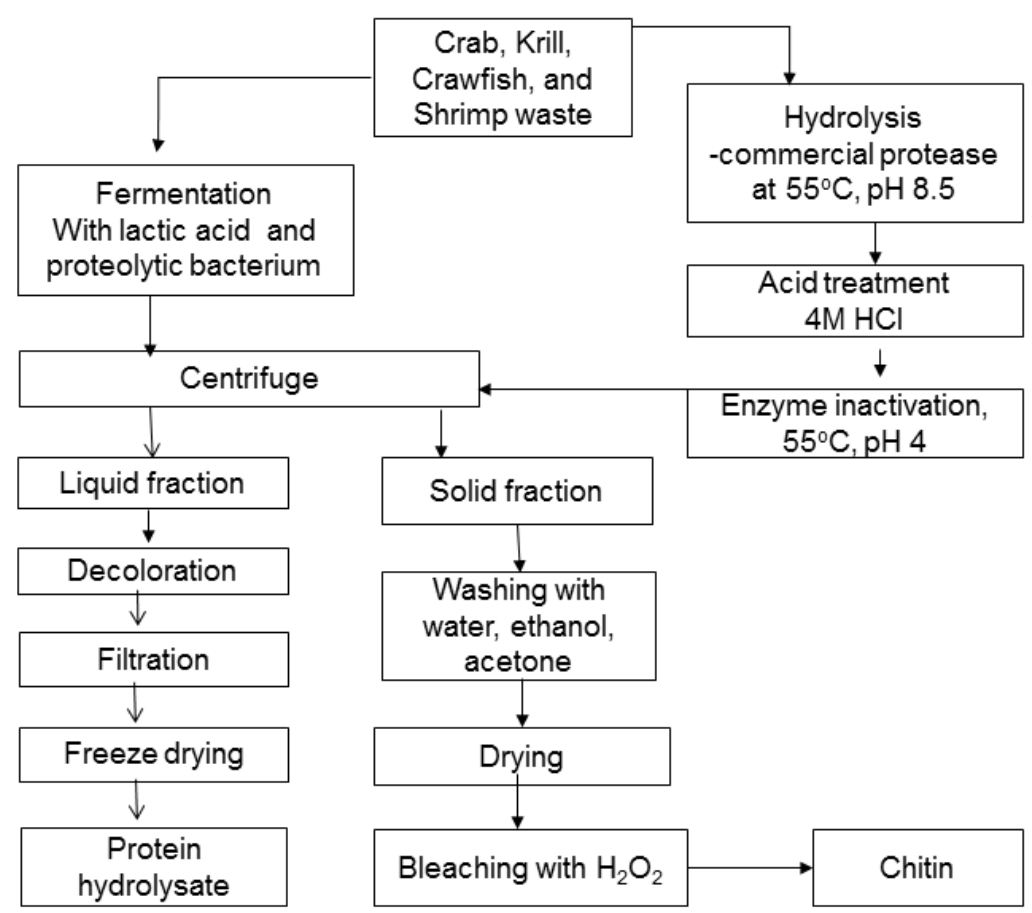

Fig. 3. Flowchart of procedure used for the extraction of chitin

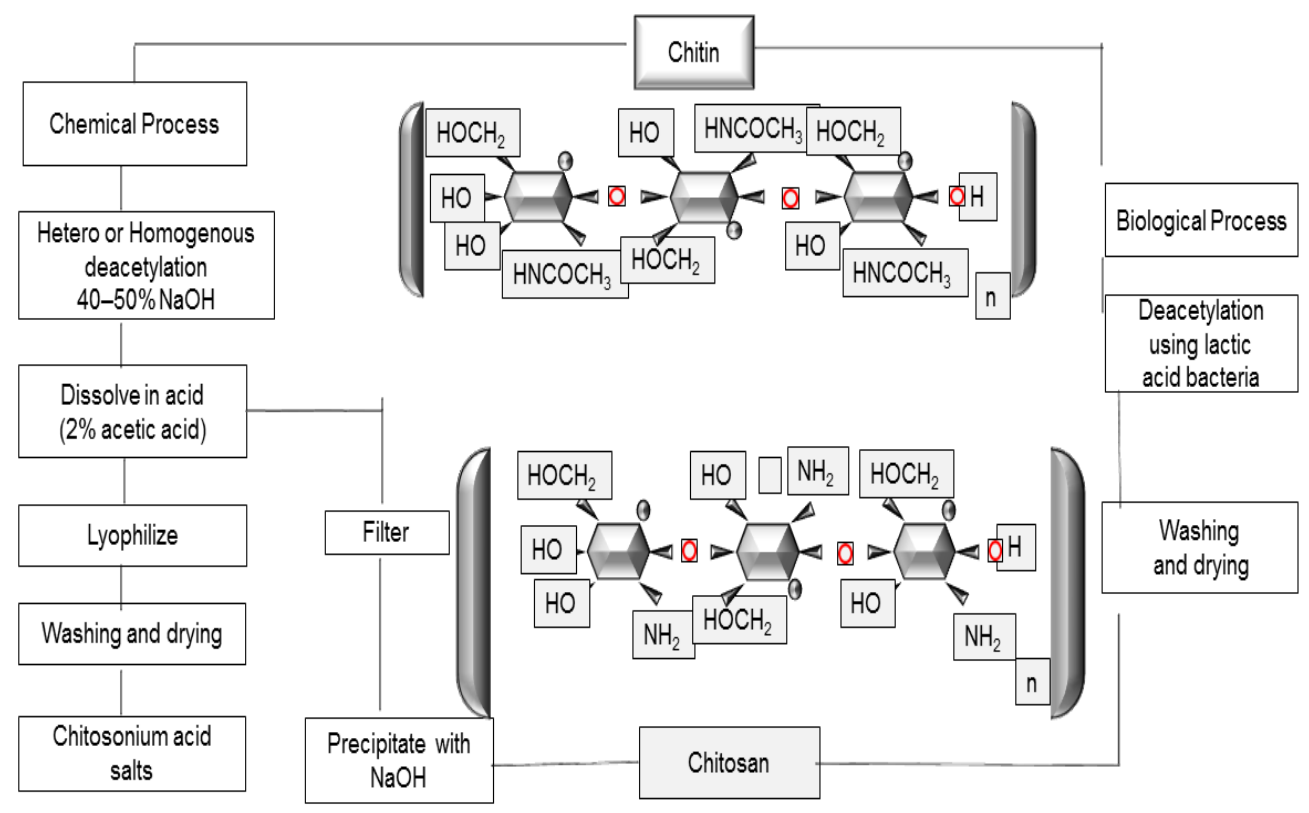

Fig. 4. General flowchart of procedure used for the biological extraction of chitin

Chitin can be processed chemically as well as biologically to produce chitin, as shown in Fig. 4. While deacetylation is done with sodium hydroxide in chemical processes, biological processes utilise lactic acid bacteria for the same. Researchers have tried to modified these processes using different agents under different reaction conditions. The extraction of chitin and CS is affected by the body parts and the type of organism used. Biological methods of CS extraction use fermentation processes for shrimp or other 
organism waste. The solid and liquid fraction can be separated to allow for chitin extraction. Demineralization and protein removal steps can be done, as was in the chemical procedure. Nessa et al. (2010) extracted chitosan from sun-dried prawn shells by producing coarse particles in a centrifugal grinding machine. Some coarse particles were demineralized with $10 \% \mathrm{HCl}$ acid at $27^{\circ} \mathrm{C}$ for $22 \mathrm{~h}$. Deproteinising was done using $\mathrm{NaOH}$ solution for $24 \mathrm{~h}$ at $70{ }^{\circ} \mathrm{C}$, then decolourization and drying under vacuum. A crispy powder of chitin was produced. Deacetylation of chitin was attained using $\mathrm{NaOH}$ for 45-72 h. The resulting chitosan was rinsed with distilled water and oven-dried. The yield of chitin was $20 \%$, and CS was 19.6\%. Tarafdar and Biswas (2013) reported extraction using two different prawn shells and shrimp waste. In the first method, $10 \mathrm{~g}$ of prawn shell waste was washed and demineralized by adding $1.5 \mathrm{~N} \mathrm{HCl}$ at $25{ }^{\circ} \mathrm{C}$ for $1 \mathrm{~h}$ followed by deproteinisation with 0.5 to $3 \% \mathrm{NaOH}$ at $100{ }^{\circ} \mathrm{C}$ for $30 \mathrm{~min}$. Deacetylation of chitin produced $\mathrm{CS}$, which was prepared by treating with $42 \%$ aqueous $\mathrm{NaOH}$ at $95{ }^{\circ} \mathrm{C}$ for $1.5 \mathrm{~h}$ and washed then dried. In the second method, $5 \mathrm{~g}$ of shrimp waste was soaked then deproteinized in an aqueous $\mathrm{NaOH}$ solution at $25^{\circ} \mathrm{C}$ for $21 \mathrm{~h}$. The deproteinized shell was demineralized by $4 \% \mathrm{HCl}$ at $25{ }^{\circ} \mathrm{C}$ for $12 \mathrm{~h}$. The chitin was dried at ambient temperature. CS was obtained by treating chitin with $50 \%$ aqueous $\mathrm{NaOH}$ at $40{ }^{\circ} \mathrm{C}$ for three days. CS was dried at ambient temperature. The overall procedures used in chemical, biological methods investigated in literature using insects, shellfish and fungi are shown in Fig. 5.

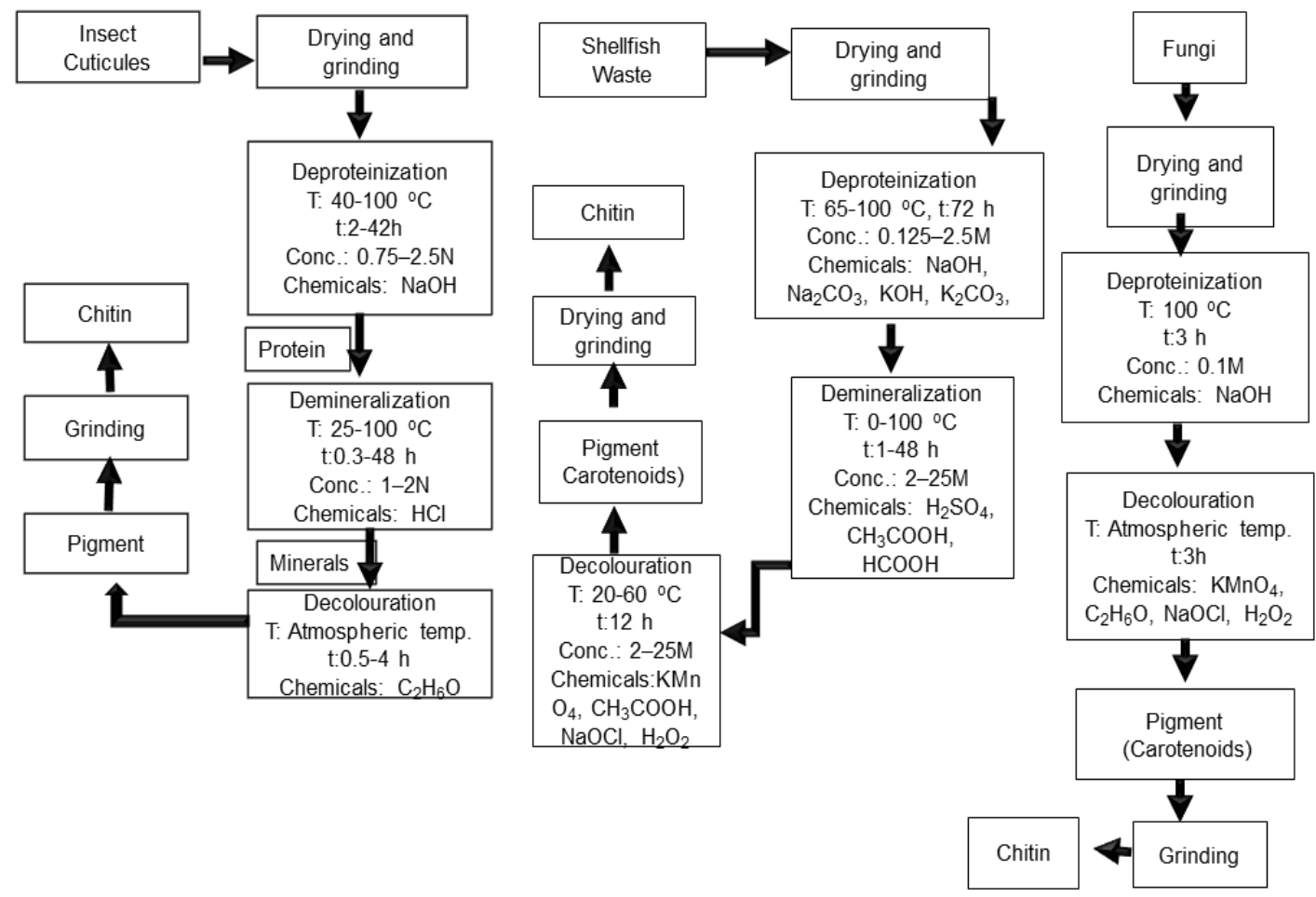

Fig. 5. Chemical and biological extraction of chitosan from chitin

Mohammed et al. (2013) extracted chitin and CS from prawn shells. Initially, frozen prawn shells were washed with boiled water then dried at $60{ }^{\circ} \mathrm{C}$. The dried prawn shells were crushed and treated with $5 \% \mathrm{NaOH}$ and refluxed at $60{ }^{\circ} \mathrm{C}$ for $2 \mathrm{~h}$, followed by acetone treatment to remove colours at $25^{\circ} \mathrm{C}$ for $24 \mathrm{~h}$. To dissolve the calcium carbonate, these were further treated with a 0.5 or $1 \% \mathrm{HCl}$ solution for $24 \mathrm{~h}$ at $25^{\circ} \mathrm{C}$. Chitosan was 
obtained by deacetylation process using $\mathrm{NaOH}$ solution at elevated temperature and concentration. After the procedure, chitosan was washed several times with distilled water and dried at $60{ }^{\circ} \mathrm{C}$ in a vacuum oven. Figure 6 depicts the relative comparison of chemical and biological processes to produce chitosan. While chemical extraction methods are quick, consume less time, and are applied on a commercial scale, they consume more energy and make protein components unsuitable for animal feed. As an alternative, biological processes offer the advantage of environmental safety and the production of valuable by-products for animal feed. Investigations to reduce the processing time and cost is still underway.

\begin{tabular}{|c|c|c|}
\hline$n_{2}$ & Chemical Extraction & Biological Extraction \\
\hline $\mid$ & $\begin{array}{l}\text { - Short time processing } \\
\text { - Chemical methods are currently being } \\
\text { applied in commercial scale }\end{array}$ & $\begin{array}{l}\text { - More environment friendly, safer } \\
\text { - Produce high-value commercial by- } \\
\text { products } \\
\text { - Lengthy processing }\end{array}$ \\
\hline 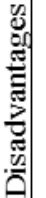 & $\begin{array}{l}\text { - Energy consuming } \\
\text { - Extremely hazardous } \\
\text { - Unsuitable protein components as } \\
\text { animal feed }\end{array}$ & $\begin{array}{l}\text { - Less economic } \\
\text { - Lengthy procedure } \\
\text { - Still not in commercial scale }\end{array}$ \\
\hline
\end{tabular}

Fig. 6. Comparison of chemical and biological extraction methods

Table 1. Chitin and Chitosan Extraction from Different Species

\begin{tabular}{|l|l|l|l|}
\hline Source & Chitin (\%) & Chitosan (\%) & Reference \\
\hline Bombyx mori & 15 to 20 & 70 to 80 & (Zhang et al. 2000) \\
\hline Bombyx mori & 2.59 to 4.23 & $73 \%$ to 96.75 & (Paulino et al. 2006) \\
\hline $\begin{array}{l}\text { Mud crab Scylla } \\
\text { tranquebarica }\end{array}$ & $\begin{array}{l}\text { Carapace: } 10.74 \\
\text { Claw: } 7.91 ; \text { Legs; } 14.62\end{array}$ & $\begin{array}{l}\text { (Thirunavukkarasu and } \\
\text { Shanmugam 2009) }\end{array}$ \\
\hline $\begin{array}{l}\text { Zophobas morio } \\
\text { (Mohammed et al. } \\
\text { 2013) }\end{array}$ \\
\hline $\begin{array}{l}\text { Leptinotarsa } \\
\text { decemlineata }\end{array}$ & 35 & 25 & (Kaya et al. 2014) \\
\hline Shrimp & 7 to 20 & 67 to 72 & (Hajji et al. 2014) \\
\hline Crab & 20 & 14.9 & (Hajji et al. 2014) \\
\hline Cuttlefish & 10 & 5.3 & (Hajji et al. 2014) \\
\hline Fomitopsis pinicola & 5 & 1.2 & (Kaya et al. 2015) \\
\hline Gryllus bimaculatus & 2.35 & 71.75 & (Kim et al. 2017) \\
\hline Zophobas morio & 4.8 to 5.4 & 1.79 & (Soon et al. 2018) \\
\hline $\begin{array}{l}\text { Brachytrupes } \\
\text { portentosus }\end{array}$ & 4.3 to 7.1 & 66 to 76 & et al. 2018) \\
\hline $\begin{array}{l}\text { Macropipus } \\
\text { holsatus }\end{array}$ & 12.23 & 2.4 to 5.8 & (Pădurețu et al. 2019) \\
\hline Potamon algeriense & 8.27 & 9.52 & (Fadlaoui et al. 2019) \\
\hline Hermetia illucens & 46 & 5.89 & (Khayrova et al. 2019) \\
\hline Hermetia illucens & 9 to 30 & 18 to 29 & (Khayrova et al. 2020) \\
\hline Hermetia illucens & 83 to 87 & 13 to 43 & (Hahn et al. 2020a) \\
\hline
\end{tabular}


Table 1 lists previous work on chitin and chitosan extraction from different species (Bolat et al. 2010; Limam et al. 2011; Isa et al. 2012). Sagheer et al. (2009) extracted protein content in chitin from the crustaceans of Arab Gulf states. Similarly, Abdou et al. (2008) reported the production of chitin and its various derivative from crustaceans. Bolat et al. (2010) reported the extraction and characterization of chitin and chitosan from the crab. Though different experimental conditions are found in the literature, mild conditions are preferable to obtain chitin and chitosan with a high percentage of the degree of acetylation (Percot et al. 2003).

\section{SPECIFIC PROPERTIES OF CS-GO COMPOSITES}

Graphene oxide (GO), a novel 2D nanomaterial, is mainly produced by the modified Hummers method from natural graphite powder. For many years it attracted significant attention due to having various properties such as being readily exfoliated into monolayer sheets, hydrophilic functional groups on its basal planes and edges, interfacial interactivity with a target matrix, and electronic properties. Covalently grafting CS onto GO sheets improves the solubility of graphene. Many researchers grafted or crosslinked the CS onto GO. Various researchers synthesised or prepared the different types of CS-GO materials such as nanoparticles, green adsorbents, casting on membranes, hydrogel and aerogels. Some of the studies are discussed here to provide insight into the chemistry of CS-GO. Studies have shown the solid electrostatic interactions occurred between the cationic CS and the negatively charged GO composites (Suri and Khandegar 2021). Horseradish-peroxidase (HRP) was adsorbed onto CS-GO through covalent bonding, which assisted in enhancing the mechanical strength of HRP at a reasonably low cost. The reusability studies specified that the HRP- CS-GO could be reused for a minimum of 5 cycles (Suri et al. 2020). Researchers have designed CS nanoparticles embedded into GO to be used for a drug delivery system. The XRD analysis showed that the composite has an amorphous structure bonded with intramolecular hydrogen bonding and excellent porous, rough surface morphology and flaky structure, as shown in Fig. 7 (Hosseini et al. 2021).

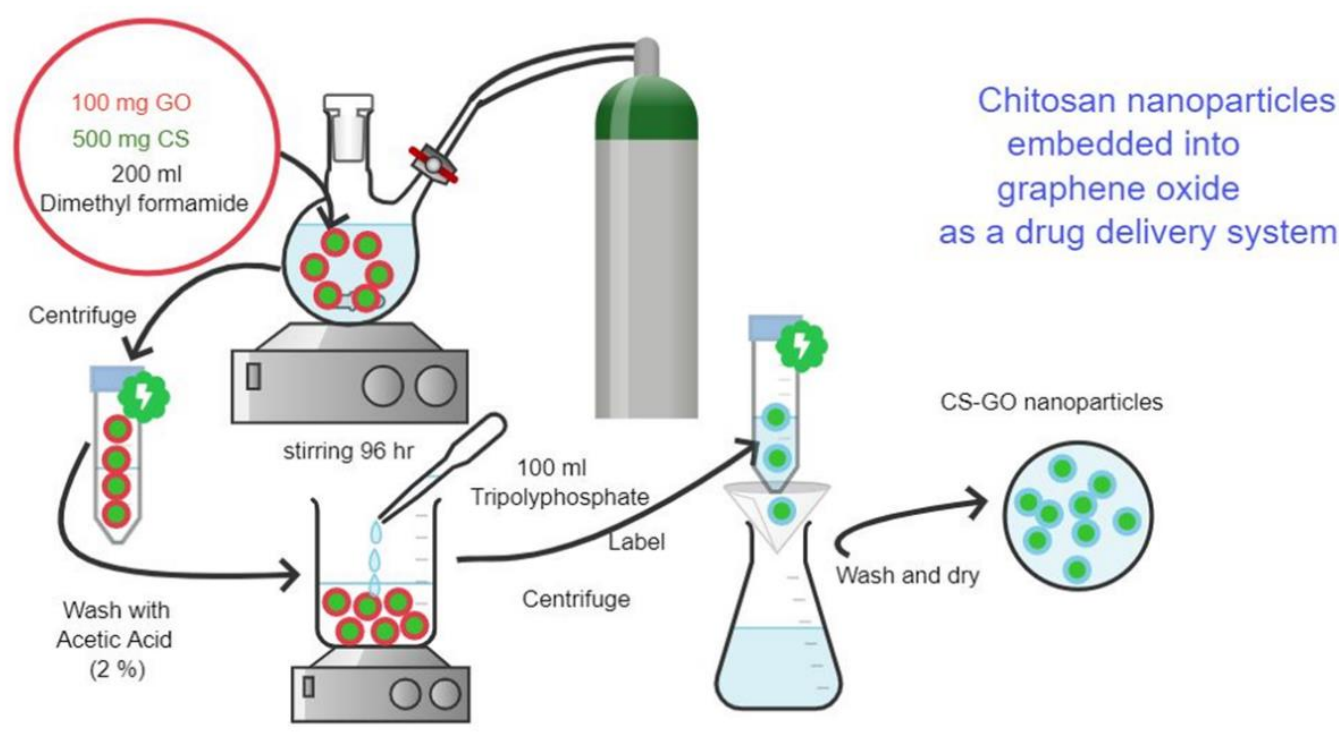

Fig. 7. Methods of synthesis of CS-GO for drug delivery system (Hosseini et al. 2021) 


\section{APPLICATIONS OF CHITOSAN COMPOSITES}

Polyfunctional CS is an organic molecule that is used in a wide range of applications. The chemical modification of CS increases the selectivity and adsorption potential of the target; amendment adjusts the Lewis basicity by introducing functional groups. These groups are different in donor ability than the amine and hydroxyl groups. Improvement can be carried out with or without crosslinking agents. Various forms of chitosan and adsorbent synthesis techniques are given in Fig. 4. GO has distinctive properties including high conductivity, flexibility, and controllable permittivity with hydrophilicity (Kostarelos and Novoselov 2014). These properties facilitate the development of GO-based multifunctional biomedical devices. Therefore, GO has been developed in different sizes and forms by the chemical modifications process. GO is made by chemical exfoliation of graphite powders through strong oxidants (Wang et al. 2013b). It shows high specific surface area (e.g. 2,600 $\mathrm{m}^{2} / \mathrm{g}$ ) (Sponza and Alicanoglu 2017). This property can help as a support medium to make the nanoparticles without accumulation in the adsorption process. Graphene consists of a single layer of $\mathrm{sp}^{2}$ bonded carbon atoms. Graphene is the thinnest material and the most robust material due to its particular thermal, mechanical, optical, and electrical properties (Geim 2009). Oxygen functionalities in GO permit the interactions with the positive ion and provide active sites for the nucleation and growth of nanoparticles (Guria et al. 2016).

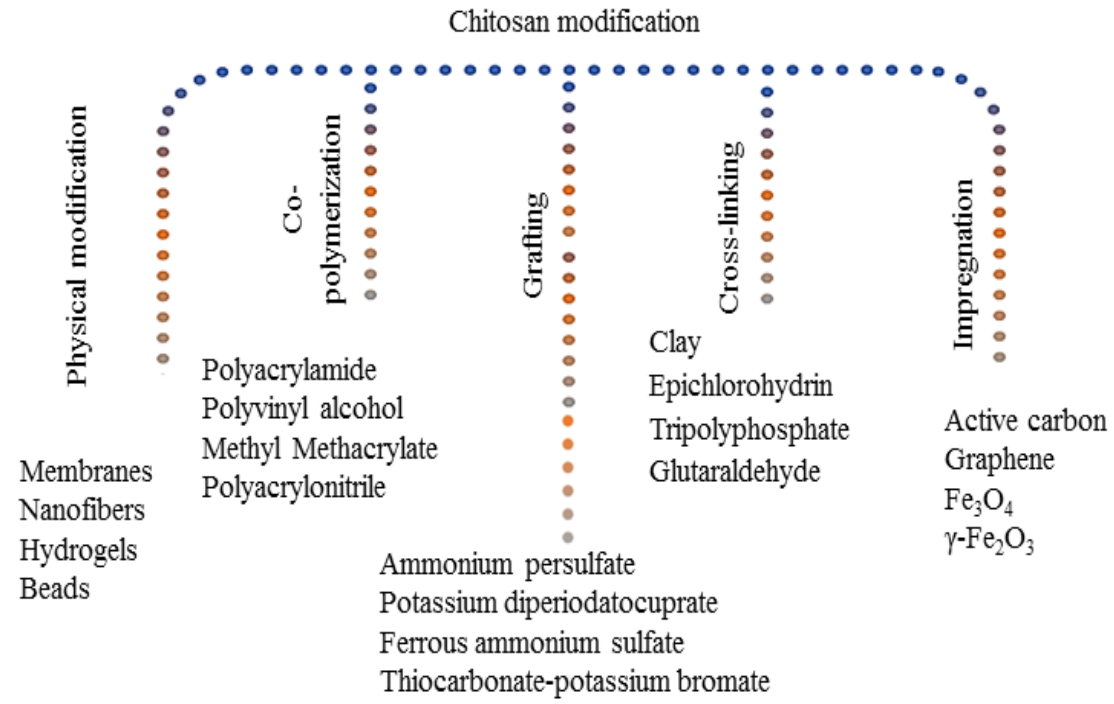

Fig. 8. Forms and modification of chitosan to improve its properties

GO has plenty of functional groups and high mechanical strength as the prospective material for removing heavy metals (Menazea et al. 2020). However, inter-functional solid bonds between graphene sheets result in static surface chemical properties, lower surface area, and poor aqueous solutions dispersion. Reduced adsorption efficiency limits its use in wastewater treatment (Li et al. 2009b). CS and GO-based nanocomposites can be used in several cosmetics, as a fixative in photography, and as an adsorbent and flocculating agent in wastewater treatment, in the paper and textile units agriculture sector (Dutta et al. 2004; Philibert et al. 2017). Chemical, physical, or combinations of both modes of modification are used for CS. The physical transformation comprises blending and conversion of chitosan's forms. The physical change leads to expansion of the polymer 
chains of chitosan. As a result, internal sorption sites increase, and their crystalline state decreases. Blending chitosan with active carbon, graphene, $\mathrm{Fe}_{3} \mathrm{O}_{4}, \gamma-\mathrm{Fe}_{2} \mathrm{O}_{3}$, and clay is another suitable method for synthesizing better strength, adsorption, sensitivity, and magnetism property nanocomposite (Badry et al. 2017; Wang and Zhuang 2017). Chitosan modifications by chemical treatments are either crosslinking or graft co-polymerisation. Chemical changes improve complex formation properties with metal ions and surfactants (Rinaudo 2006; Alves and Mano 2008). Different cross-linkers such as epichlorohydrin, tripolyphosphate, and glutaraldehyde are used to modify (Mojiri et al. 2019). Homogeneous crosslinking of chitosan improves metal binding capacity relative to heterogeneous cross-linking (Varma et al. 2004). Figure 8 shows the different forms and modifications of CS, which can help to strengthen its properties.

\section{Biomedical Applications}

A drug delivery system is defined as a formulation or a device that enables the administration of a therapeutic substance or active pharmaceutical ingredient in the body, improves its efficacy as well as safety by controlling the rate, time, and place of release of drugs (Jain 2020). Researchers have investigated the potential of nanoparticles such as dendrimers, liposomes, self-assembling peptides, water-soluble polymers, and polymeric micelles as effective drug delivery agents. They find unique applications for cancer treatment where nanoparticulate drug carriers improve cure efficacy by reducing off-target systemic toxicity and passive drug targeting to tumour cells or tissues (Yu et al. 2016; Edgar and Wang 2017). Graphene oxide (GO), reduced graphene oxide, and graphene quantum dots have shown high surface area, which provides sufficient drug loading capacity along with biocompatibility. Functionalization of GO or reduced GO with polyethene glycol, mannose, and sulfonic acid conjugated to folic acid has improved biodegradability, biocompatibility, and thermosensitivity, facilitates $\mathrm{pH}$-dependent and targets specific controlled release of the drug to tumour cells (Karki et al. 2020). Also, GO displays low uptake in the reticuloendothelial system and extended blood circulation time (Zhao et al. 2018). Still, these GO-based nanocomposite systems have limitations related to drug solubility (colloidal instability due to aggregation), controlled and targeted drug release to cancer cells, hemolytic properties, and in vivo toxicity (McCallion et al. 2016; Karki et al. 2020). Extensive research is being carried out to identify new and novel functional groups for GO modifications, where CS has emerged as an excellent helpful natural modifier of GO. CS-based nanocomposites are biocompatible, non-toxic, and display increased drug efficacy (Thakur and Thakur, 2014). Due to their small size, these nanoparticles or nanocomposites can move through blood-brain barriers, thus using efficient drug delivery systems (Li et al. 2018). Despite the above advantages, owing to its low solubility and poor mechanical properties, the application of CS is still minimal. Different formulations of CS and its composites with several other compounds are being worked upon to increase targeted drug action and efficacy for drug delivery systems (Ali and Ahmed 2018; Li et al. 2018; Ashrafizadeh et al. 2019).

\section{Drug delivery system}

Derivatized chitosan has been used to modify GO to prepare nanocomposites for drug delivery to cancerous cells. Rana et al. (2011) developed chitosan-graphene oxide nanocomposites. The chitosan-functionalized graphene oxides served as a drug delivery system, which was loaded with Ibuprofen and 5-fluorouracil. It displayed controlled release and long term biocompatibility in human lymphoblastic leukemia and MCF7-human breast 
cancer cells. Another functionalized nanocarrier based on CS-GO nanocomposite was prepared by Bao et al. (2011) through the amidation process. CS-GO nanocomposite was applied to load the anti-cancer drug Camptothecin. Cell toxicity was analyzed against HepG2 and HeLa cancer cells using MTT assay, where a 50\% growth inhibition concentration was observed at $29 \mu \mathrm{m}$. Thus, the novel nanocarrier was potent against cancer cells. An in vitro drug release experiment showed that $17.5 \%$ camptothecin could be released. This CS-GO nanocomposite camptothecin complex exhibited enhanced stability and a high loading capacity.

Yang et al. (2016) modified GO with carboxymethyl chitosan and further conjugated it with hyaluronic acid and fluorescein isothiocyanate. This conjugate combination was used as a drug delivery vehicle for doxorubicin, a model anti-cancer drug, to study in vitro release behaviour. It specifically targeted cancer cells and inhibited the growth of HeLa, CD44 overexpressing cells. It exhibited $\mathrm{pH}$-dependent release and a drug loading efficiency of 95\%. Pan et al. (2016) developed a GO-CS nanocomposite by conjugating GO with carboxymethyl chitosan, fluorescein isothiocyanate, and lactobionic acid to be used as a targeted anti-cancer drug delivery system; nanocomposite without LA conjugate was used as the control. Functional group lactobionic acid is recognized explicitly by asialoglycoprotein receptors overexpressed on cancerous hepatic cells. High drug loading content and efficiency of $>96 \%$ was observed in SMMC-7721 cancer cells. The $\mathrm{pH}$-sensitive release of the nanocomposite was followed, which is typical due to reduced $\mathrm{pH}$ microenvironment of cancerous cells. Higher uptake was observed using this nanocomposite for SMMC-7721 cancer cells through confocal microscopy and cell toxicity assays, strengthening its use as an anti-cancer drug delivery system. Further, Wang et al. (2018) synthesized a galactosylated CS-GO-doxorubicin drug delivery system against hepatocellular carcinoma. The action of the synthesized composite was investigated against HepG2 and SMMC-7721 hepatocarcinoma cell lines. After coating glycosylated-CS over the surface of GO, drug loading capacity was found to be $98 \%$. Drug release to hepatic carcinoma cells was studied using cellular assays such as cell proliferation and cellular uptake assay. An in vivo anti-tumour efficacy study showed efficient inhibition of tumour cells as compared to control. The above drug conjugated system might be used as biomedicine and may effectively target liver cancer cells.

In another study, developed chitosan/sodium alginate products were functionalized using magnetic GO-based nanocomposites and were loaded with doxorubicin. The functionalized magnetic graphene oxide nano sheets have high drug loading efficiency (Xie et al.2019). A nanocarrier system based on reduced-GO was loaded with doxorubicin and coated with CS for stabilization was developed, which displayed high biocompatibility and efficiency for entrapping doxorubicin $(\sim 65 \%)$ and depicted controlled release $(\sim 50 \%$ release in $48 \mathrm{~h}$ ). Furthermore, it was demonstrated to precisely deliver doxorubicin intracellularly in PC-3 prostate cancer cells with cytotoxicity $>65 \%$ (SreeHarsha et al. 2019). Researchers have also synthesized folic acid coupled CS and GO nanocomposites. These composites were used for loading polyprenol and fullerene. They depicted good drug loading and encapsulation efficiency, drug release property, and storage stability. Also, cytotoxicity analysis of this nanocomposite in human hepatic cell line $\mathrm{MHCC} 97 \mathrm{H}$, exhibited greater inhibition capacity than regular human hepatic non-cancerous cell line (Tao et al. 2019). Shi et al. (2016) also prepared carboxymethyl-CS-GO-based nanoparticles using the electrostatic droplet generation method, which effectively adsorbed gatifloxacin, ofloxacin bovine serum albumin, lysozyme, and doxorubicin hydrochloride (Tao et al. 2019). Very recently, Anirudhan et al. (2020) synthesized CS and folic acid 
nanocomposite by conjugating through $N, N^{\prime}$-dicyclohexylcarbodiimide coupling. Furthermore, itaconic acid and acrylic acid monomers were grafted to the hydroxyl groups of prepared nanocomposites to generate $-\mathrm{COOH}$ functional groups and combined with modified amine GO. Further, the anti-tumour drug was loaded onto the modified amine CS-GO conjugated folic acid nanocomposite through $\pi$ - $\pi$ stacking and hydrogen bonding interactions. The loading capacity of doxorubicin in the polymeric matrix was determined to be $95 \%$. An advanced CS-GO hybrid-responsive system of enhanced biocompatibility, high doxorubicin-loading ability, and tumour-inhibition efficacy was developed.

Table 2. CS-GO Nanocomposites with Chemotherapeutic Activity Against Cancer Cells

\begin{tabular}{|c|c|c|c|}
\hline Nanocomposite/Drug Composite & Drug Conjugated & $\begin{array}{l}\text { Type of Cancer or } \\
\text { Cancer Cell Line }\end{array}$ & References \\
\hline CS-GO & Camptothecin & $\begin{array}{l}\text { HepG2 and HeLa } \\
\text { cell lines }\end{array}$ & $\begin{array}{l}\text { Bao et al. } \\
(2011)\end{array}$ \\
\hline Chitosan-functionalized GO & $\begin{array}{l}\text { Ibuprofen and 5- } \\
\text { fluorouracil }\end{array}$ & $\begin{array}{l}\text { CEM human } \\
\text { lymphoblastic } \\
\text { leukemia and } \\
\text { MCF7-human } \\
\text { breast cancer }\end{array}$ & $\begin{array}{l}\text { Rana et al. } \\
(2011)\end{array}$ \\
\hline $\begin{array}{l}\text { GO conjugated with } \\
\text { Carboxymethyl chitosan, } \\
\text { hyaluronic acid and fluorescein } \\
\text { isothiocyanate }\end{array}$ & Doxorubicin & $\begin{array}{l}\text { HeLa, CD } 44 \text { over- } \\
\text { expressed cells }\end{array}$ & $\begin{array}{l}\text { Yang et al. } \\
(2016)\end{array}$ \\
\hline $\begin{array}{l}\text { GO conjugated with } \\
\text { carboxymethyl chitosan, } \\
\text { fluorescein isothiocyanate, and } \\
\text { lactobionic acid }\end{array}$ & Doxorubicin & $\begin{array}{l}\text { SMMC-7721 } \\
\text { cancer cells }\end{array}$ & $\begin{array}{l}\text { Pan et al. } \\
(2016)\end{array}$ \\
\hline $\begin{array}{l}\text { Functionalized GO with CS } \\
\text { sodium alginate }\end{array}$ & Doxorubicin & $\begin{array}{l}\text { MCF-7 Human } \\
\text { Breast cancer cell } \\
\text { line }\end{array}$ & Lei et al. (2016) \\
\hline $\begin{array}{l}\text { Galactosylated CS-GO- } \\
\text { doxorubicin }\end{array}$ & Doxorubicin & $\begin{array}{l}\text { HepG2 and } \\
\text { SMMC- } 7721 \\
\text { hepatocarcinoma } \\
\text { cell lines }\end{array}$ & $\begin{array}{l}\text { Wang et al. } \\
(2018)\end{array}$ \\
\hline $\begin{array}{l}\text { Dispersion of } \mathrm{GO} \text { Ag nanohybrid } \\
\text { particles in the chitosan } \\
\text { hydrogel matrix }\end{array}$ & Doxorubicin & $\begin{array}{l}\text { Human colon } \\
\text { cancer cells } \\
\text { (SW480) }\end{array}$ & $\begin{array}{l}\text { Rasoulzadehza } \\
\text { li and Namazi } \\
\text { (2018) }\end{array}$ \\
\hline $\begin{array}{l}\text { Magnetic GO nanosheets } \\
\text { functionalized with CS and } \\
\text { sodium alginate through non- } \\
\text { covalent layer-by-layer self- } \\
\text { assembly }\end{array}$ & $\begin{array}{l}\text { Doxorubicin } \\
\text { hydrochloride }\end{array}$ & $\begin{array}{l}\text { Human lung } \\
\text { cancer cell line } \\
\text { (A549) }\end{array}$ & $\begin{array}{l}\text { Xie et al. } \\
(2019)\end{array}$ \\
\hline Folic acid coupled CS-GO & $\begin{array}{l}\text { Ginkgo Biloba } \\
\text { Leaves polyprenol } \\
\text { and Fullerene } \\
\text { (C60F) }\end{array}$ & $\mathrm{MHCC} 97 \mathrm{H}$ & $\begin{array}{l}\text { Tao et al. } \\
(2019)\end{array}$ \\
\hline $\begin{array}{l}\text { Chitosan-based hybrid } \\
\text { nanoparticle of DOX-loaded } \\
\text { reduced form of GO }\end{array}$ & Doxorubicin & $\begin{array}{l}\text { Prostate cancer } \\
\text { cells PC-3 }\end{array}$ & $\begin{array}{l}\text { SreeHarsha et } \\
\text { al. (2019) }\end{array}$ \\
\hline $\begin{array}{l}\text { Amine functionalized GO } \\
\text { conjugated with chemically } \\
\text { modified CS with folic acid }\end{array}$ & Doxorubicin & $\begin{array}{l}\text { MCF7 and Hela } \\
\text { cells }\end{array}$ & $\begin{array}{l}\text { Anirudhan et } \\
\text { al. (2020) }\end{array}$ \\
\hline
\end{tabular}


For hybrid preparation, deprotonated carboxyl of GO nanoparticles and the protonated amine of CS's backbone were allowed to self-assemble. The developed hybrid was loaded with doxorubicin and displayed charge reversal from negative charge during blood circulation $(\mathrm{pH} 7.4)$ to positive charge at tumour extracellular microenvironment $(\mathrm{pH}$ 6.5). Biocompatibility, cell toxicity, in-vitro triggered release, and intracellular uptake of the prepared nanocomposite were studied in HepG2 cells; cell viability of HepG2 cells upon treatment the nanohybrids were found to be around 96\% (Zhao et al. 2018). Another drug delivery system was synthesized by Rasoulzadehzali and Namazi (2018) by dispersion of GO-Ag particles in the CS-based hydrogel matrix for controlled release of doxorubicin, and a sustained-controlled drug release profile was observed. Additionally, Lei et al. (2016) developed another nanocarrier with functionalized graphene oxide, chitosan, and sodium alginate. The composite displayed significant $\mathrm{pH}$-dependent doxorubicin release behaviour and cytotoxicity in MCF7 anti-cancer cells.

Over the last decade, different research groups have used vivid strategies to generate CS-GO drug delivery systems with many drugs, as summarized in Table 2 . These studies support the application of graphene-chitosan based material as a chemotherapeutic agent. These new drug delivery systems promise targeted delivery, controlled release, and enhanced therapeutic efficiency of many anticancer drugs for cancer treatment.

\section{Antimicrobial properties}

Microbial infection is responsible for a plethora of diseases. Anti-microbials are agents that target microbes such as bacteria, fungi, protozoans, and viruses. Antibiotics are used widely to treat bacterial infections; however, antibiotic resistance has become a significant public health challenge as multidrug-resistant microorganisms are steadily rising. Nanotechnology-based antibiotics or nanobiotics have promising results in targeting antibiotic resistance in several diseases. These nanoparticles act through multiple mechanisms, load multiple drugs onto a single nanoparticle, thereby reducing the chances of antibiotic resistance. Metal-containing nanoparticles, chitosan-containing nanoparticles and graphene-based nanoparticles, cationic liposomes, and dendrimers are a few examples (Pelgrift and Friedman 2013; Gómez-Núñez et al. 2020; Vassallo et al. 2020). Due to its structure, graphene has intrinsic anti-bacterial activity. Hence in nanoparticles based on graphene, bacterial cell walls and membranes are damaged by sharp edges of graphene, leading to the release of intracellular content followed by bacterial cell death. The generation of reactive oxygen species has been speculated as another cause (Gómez-Núñez et al. 2020).

The antimicrobial effectiveness of CS-containing nanoparticles is probably due to their cationic nature. These particles associate with negatively charged cell walls or membranes on bacterial cells, altering their permeability leading to efflux of cytoplasmic contents and eventually bacterial cell death. These nanoparticles can associate with negatively charged bacterial DNA and chelates metal ions necessary for the functioning of enzymes and membrane integrity, thereby exerting solid antimicrobial activity (Pelgrift and Friedman 2013; Yilmaz Atay 2019). CS-GO based nanocomposites display intense antimicrobial action against bacteria, fungi, and yeasts. Over the last decade, many research groups have developed several CS-GO-based nano-composites with different functional groups having potent anti-microbial activity. Keshvardoostchokami et al. (2020) synthesized GO-based silver nanocomposites, where CS was used as a substrate. A broadspectrum antibacterial activity of these nanocomposites was observed against both Grampositive (C. glutamicum) and gram-negative bacterium (E. coli strain DH5 $\alpha$ ). 
Approximately $5 \mu \mathrm{L}(2 \mathrm{~g} / \mathrm{L})$ of the nanocomposite efficiently reduced $10^{8}$ colony-forming units $(\mathrm{CFU}) / \mathrm{ml}$ to zero. An antimicrobial biofilm from CS-iron oxide coated GO hydrogel (CH-GIO) displayed robustness and, during characterization, showed significantly improved mechanical and thermal properties. Hydrogel biofilm incredibly worked against both Gram-positive and negative bacterial species such as $S$. aureus (methicillin-resistant), S.aureus, E. coli, and against fungus $C$. albicans. The effect was assessed by agar diffusion and cell viability assay using MTT dye. $10^{5} \mathrm{CFU} / \mathrm{mL}$ of bacteria were seeded onto agar plates. Upon treatment with CS-GO films, the cell population was reduced to zero, possibly due to the generation of reactive oxygen species when these particles enter through the cell membrane.

Further, post-treatment with CS-GO films, the cell viability of mouse L929 fibroblastic cells were 80 to $93 \%$ higher than controls, thus confirming the non-cytotoxic nature of the synthesized films. The least inhibitory concentration value of CS-GO against E. coli was 32 (g/ml) (Li et al. 2016). Another composite, AgO-CoO-CdO/Poly(alanine)chitosan-reduced graphene oxide (PACSGO) nanocomposite was developed by Zhang et al (2020). This composite worked as a nano-photocatalyst for the substantial degradation of organic dye compounds from water. Additionally, the group reported enhanced antibacterial activity against S.aureus, E. coli, P. aeruginosa, and B. cereus medium and increased inhibition zone value with the addition of the nanocomposites. This nanocomposite showed a higher percentage of scavenging activity of $\mathrm{AgO}-\mathrm{CoO}-\mathrm{CdO} /$ PACSGO than other composites.

de Faria et al. (2015), using GO and silver particles nanocomposites, fabricated electrospun mats, where the blend of CS and poly(lactide-co-glycolide) (PLGA) was used as biopolymeric fibre. These PLGA/chit-GOAg electrospun mats displayed a bacterial inactivation rate of $\sim 98 \%$ for $E$. coli and $P$. aeruginosa compared to control (nonmodified control PLGA-chitosan). A lower inactivation rate of $79.41 \%$ was observed against $S$. aureus due to a thick peptidoglycan layer in the cell wall of Gram-positive bacteria. Additionally, Yang et al. (2019) synthesized an antibacterial nano agent by coating quaternized chitosan (QCS) on the surface of $\mathrm{Fe}_{3} \mathrm{O}_{4}$ nanoparticles-anchored GO. This nanocomposite killed pathogens upon generation of hyperthermia through photothermal near infra-red irradiation.

The anti-bacterial efficacy of CS-GO based film was also investigated in detail by Marin et al. (2019). Electrospun CS-GO-and polyvinyl alcohol-based composite nanofibrous membrane was synthesized and analyzed. With the percentage of GO at $1 \%$, the scaffold membrane showed antibacterial properties against gram-positive bacteria, $B$. cereus and S. aureus, and gram-negative bacteria, S. enterica and E. coli. The anti-bacterial inhibitory effect of the electrospun nanocomposite scaffold might be due to GO, as its edges penetrate the cell membrane, leading to membrane rupture and lipid peroxidation. Thus, the nanofibrous composite membrane might be used as a scaffold in exposed wounds and infected areas where the risk of bacterial infection is grave. Khalil et al . (2020) also showed that GO-CS and GO-EDTA based nanocomposites display anti-microbial activities against E. coli, $S$. aureus, and $C$. albicans. There have been a few pre-clinical investigations on their wound healing applications (Moradi et al. 2021). For instance, a temporary skin graft was made of CS-polyvinyl pyrrolidone-GO nanosheets. Live and dead assays were performed in-vitro. Cell viability and bactericidal capacity of this membrane were increased by using GO in the sheet. Accelerated healing tests were done using the rat's skin. A period of 14 days was required for complete regeneration of skin at a large wound. Nanosheet made of CS-GO covering was able to heal the wound almost completely 
(>99\%) after 21 days following the injury (Mahmoudi et al. 2017).

CS-GO-PVA composite was prepared using synthesized guanidine modified GO with $(0,0.1,0.2,0.5$, and $1.0 \mathrm{wt} \%)$. In-vivo experiments validated that CS-GO ().5\%)-PVC sheets had a high antibacterial activity (50\% more than GO used alone). In vivo studies on mice had shown $41 \%$ faster wound healing capacity than the control (Chen et al. 2020). The synergistic effect was observed on combining CS-GO-polylactic acid (PLLA) for wound healing. CS-PLLA-based scaffolds were coated with GO. Pig iliac endothelial cells and female Sprague-Dawley rats were used for cytocompatibility and wound healing investigations. GO-coated CS/PLLA scaffolds resulted in a $60.48 \%$ decrease in the size of the wound. The wound was recovered in 21 days that shows its effectiveness as a woundhealing material. The scaffold was an effective bactericidal agent against E. coli and S. aureus (Yang et al. 2021).

\section{Environmental Applications}

CS finds extensive application in removal of metals in water treatment, as the amine and hydroxyl groups present in it easily form chelates with metal ions. CS-based membranes are reported to be useful to treat wastewater (Thakur and Voicu 2016). CS's insolubility in water and alkaline solution can be modified by GO, an excellent adsorbent with a high surface area. The self-agglomeration of GO is a limiting factor for its more comprehensive application. Various researchers have attempted to synthesis composite material using CS-GO. The negative charges on the surface of aqueous dispersed G sheets bond chemically with the cationic group present in chitosan's amino polysaccharides. Carboxylic groups of GO react through the amine group of CS, in some cases creating an amide bond between them. Various modifying agents such as EDTA can be added to the composite to functionalize these composites further. There is a wide range of applications of these composites, varying from water purification to electrode development. Most studies have been performed using optimization of parameters including solution properties including $\mathrm{pH}$, temperature, an initial amount of adsorbent, contact time, swelling behaviour, and adsorbent properties such as its amount, form, and recyclability. Many active sites and more adsorbate in the waste stream have led to a higher mass gradient between solution and adsorbate. The ease of separation of adsorbents from the waste stream is also an essential factor influencing the adsorbent's broad choice.

\section{Removal of heavy metals}

Various functional groups including epoxy, hydroxyl, and carboxylic in GO provide oxygen to bind with metal ions. Likewise, amino groups present in CS binds with metal ions and can adsorb them from contaminated effluent. However, various limitations, including low operation efficiency, stability, and aggregation, are related to graphene oxide and chitosan usage alone. Hence, scientists have performed studies to crosslink and functionalize CS with polar groups such as graphene oxide. The modification of CS-GO composite has been performed using various materials. Table 3 lists multiple metals, CSGO, and their modified composites and maximum adsorption efficiency. The research work shows its potential for adsorption of metals like $\mathrm{Cu}, \mathrm{Cr}, \mathrm{As}, \mathrm{Pb}, \mathrm{Hg}, \mathrm{Au}, \mathrm{Pd}$. Heavy metals such as $\mathrm{Cr}(\mathrm{VI})$ can lead to severe hazardous effects on the environment and human beings. While $\mathrm{Cr}(\mathrm{III})$ is an essential trace nutrient, it is limited in drinking water to 170 (mg/L) by WHO (Altundogan 2005).

On the other hand, $\mathrm{Cr}(\mathrm{VI})$, occurring as chromate and dichromate, is a mutagen and carcinogen. The Word Health Organization limit of $\mathrm{Cr}$ (VI) in drinking water is 0.050 
$\mathrm{mg} / \mathrm{L}$, an excess of which may lead to various skin diseases and even cancer in human beings (WHO 1997). Multiple researchers have investigated CS-GO nanocomposites as an adsorbent to remove chromium (Anush et al. 2020; Samuel et al. 2018). Samuel et al. (2018) showed that this composite on exposure to chromium contaminated water possesses an adsorption capacity of $104.2 \mathrm{mg} / \mathrm{g}$ at $\mathrm{pH} 2.0$ for the contact time of $420 \mathrm{~min}$ recyclability of 10 times. Copper and chromium metals were removed using a composite of CS-GO modified using 3-(p-anisyl)-4-formylsydnone by Anush et al. (2020). They studied wastewater contaminated with copper and chromium and reported that the pseudo-secondorder kinetic reaction that followed Langmuir isotherm-model was best for their study.

Furthermore, the metal removed was a vital function of initial metal concentration in the water to be treated. The maximum removal capacity for $\mathrm{Cu}$ (II) and $\mathrm{Cr}$ (VI) was found to be 111.1 and $142.8(\mathrm{mg} / \mathrm{g})$, respectively. The reaction was a thermodynamically favourable process, being spontaneous and endothermic. Arsenic is a heavy metal and a prominent constituent of industrial waste. The World Health Organization has set the limit of $10(\mu \mathrm{g} / \mathrm{L})$ in drinking water (Minatel et al. 2018). Arsenic is a toxic metal released into the ecosystem through industrial activities. Entering the food chain causes nephrotoxicity, diabetes, cardiovascular, pulmonary, and skin diseases (De Loma et al. 2019). Functionalized CS-GO composite can be used as a potential adsorbent for arsenic removal from the aqueous medium. Kumar and Jiang (2016) reported that GO and CS composite performance depends on $\mathrm{pH}$ of the solution. Their study's optimum $\mathrm{pH}$ was 4.3 to 6.5 for As (V) removal with endothermic, spontaneous metal adsorption process, which follows a pseudo-second-order kinetic model. The composite was able to adsorb As(III) and As(V) with the maximum adsorption capacity of 64.2 and $71.9(\mathrm{mg} / \mathrm{g})$, respectively, with material recyclability of 3 cycles.

CS-GO composite's functionalization using gadolinium resulted in improved efficiency to separate arsenic from aqueous medium. This composite's enhanced adsorption capacity of $252.1(\mathrm{mg} / \mathrm{g})$ showed its potential to treat arsenic-contaminated wastewater (Choi et al. 2020). The adsorption capacity of GO-Gagolinium without chitosan is much lower than the composite modified using chitosan 216.7 (mg/g) (Lingamdinne et al. 2021). Graphene oxide and reduced graphene oxide mixed with magnetic particles removed As(III) and As(V) from the aqueous solution. The studies showed that treatment time, initial arsenic concentration, $\mathrm{pH}$, temperature, anions, and humic acid affected the composite's arsenic removal efficiency. Likewise, magnetically modified CS-GO nanoparticles were efficient for Ni (II) adsorption from waste-water with the maximum adsorption of 12.2 (mg/g) (Tran et al. 2019). Mercury is also a harmful metal and is one of the major pollutants in river water. Chitosan was investigated as filler material inside the GO matrix to form CS-GO nanocomposite. GO, and CS adsorption capacity improved from $381 \mathrm{mg} / \mathrm{g}$ to $397 \mathrm{mg} / \mathrm{g}$ upon nano filling magnetically modified CS into GO matrix (Kyzas et al. 2014). EDTA was used to alter the properties of the CS-GO composite. Magnetically modified CS-GO composites were functionalized using EDTA and were found to be potential adsorbents for metals like $\mathrm{Pb}$ (II), $\mathrm{Cu}$ (II), and As (III) (Shahzad et al. 2017a). The CS-GO composite was prepared by freeze-drying and investigated for selectivity of lead metal. The composite prepared by adsorption with $5 \mathrm{wt} \% \mathrm{GO}$ in CSGO exhibited high mechanical strength and the maximum $\mathrm{Pb}$ (II) adsorption as $99 \mathrm{mg} / \mathrm{g}$ (He et al. 2011). Attempts were made to prepare the membrane by combining EDTA, GO, and $\mathrm{CS}$ to remove $\mathrm{Pb}$ (II). The adsorption efficiency using CS/EDTA/GO (0.3\%) membrane was obtained at 889 (mg/g) (Croitoru et al. 2020). Studies on the adsorption capacity of this membrane for other heavy metals can also be undertaken. 
Table 3. CS-GO Nanocomposites for Heavy Metal Removal

\begin{tabular}{|c|c|c|c|}
\hline Adsorbent & $\begin{array}{l}\text { Heavy } \\
\text { Metal }\end{array}$ & $\begin{array}{l}\text { Adsorption } \\
\text { Capacity }(\mathrm{mg} / \mathrm{q})\end{array}$ & Reference \\
\hline CS with PVA & $\begin{array}{l}\mathrm{Cr}(\mathrm{VI}) \\
\mathrm{Cu}(\mathrm{II}) \\
\mathrm{Zn}(\mathrm{II})\end{array}$ & $\begin{array}{l}3.5 \\
5.3 \\
2.8\end{array}$ & (Jaros et al. 2005) \\
\hline Magnetic CS and GO & $\begin{array}{l}\mathrm{Au}(\mathrm{III}) \\
\mathrm{Pb}(\mathrm{II})\end{array}$ & $\begin{array}{l}\mathrm{Au}(\mathrm{III})): 1076.6 \\
\mathrm{~Pb}(\mathrm{II}): 216.9\end{array}$ & (Liu et al. 2012) \\
\hline Cyclodextrin- CS and GO & $\mathrm{Cr}(\mathrm{VI})$ & 61.31 & (Li et al. 2013) \\
\hline GOCS10 & $\begin{array}{l}\mathrm{Cu}(\mathrm{II}) \\
\mathrm{Pb}(\mathrm{II})\end{array}$ & $\begin{array}{l}\mathrm{Cu}(\mathrm{II}): 70 \\
\mathrm{~Pb}(\mathrm{II}): 90\end{array}$ & (Chen et al. 2013) \\
\hline Magnetic CS and GO & $\mathrm{Pb}(\mathrm{II})$ & 76.94 & (Fan et al. 2013) \\
\hline Magnetic CS and GO & $\mathrm{Hg}(\mathrm{II})$ & 381 & (Kyzas et al. 2014) \\
\hline $\begin{array}{l}\beta \text {-cyclodextrin/magnetic } \\
\text { GO/EDTA }\end{array}$ & $\mathrm{Cr}(\mathrm{VI})$ & 68.41 & (Wang et al. 2014) \\
\hline Magnetic CS and GO & $\mathrm{Cr}(\mathrm{VI})$ & 82.14 & (Debnath et al. 2014) \\
\hline $\begin{array}{l}\text { CS and GO nanofibrous } \\
\text { composite }\end{array}$ & $\begin{array}{l}\mathrm{Cu}(\mathrm{II}), \\
\mathrm{Pb}(\mathrm{II}) \\
\mathrm{Cr}(\mathrm{VI})\end{array}$ & $\begin{array}{l}\mathrm{Cu}(\mathrm{II}): 423.8 \\
\mathrm{~Pb}(\mathrm{II}): 461.3 \\
\mathrm{Cr}(\mathrm{VI}): 310.4\end{array}$ & (Najafabadi et al. 2015) \\
\hline TGOCS & $\mathrm{Cr}(\mathrm{IV})$ & 219.5 & (Ge and Ma 2015) \\
\hline $\begin{array}{l}\text { CS and GO with disodium EDTA- } \\
2 \mathrm{Na}\end{array}$ & $\mathrm{Cr}(\mathrm{VI})$ & 86 & (Zhang et al. 2016) \\
\hline $\mathrm{CS}$ and GO & $\begin{array}{l}\text { As (III) } \\
\text { As (V) }\end{array}$ & $\begin{array}{l}\text { As (III): } 64 \\
\text { As (V): } 72\end{array}$ & (Kumar and Jiang 2016) \\
\hline CS-GO and CS/rGO & $\mathrm{Cu}$ (II) & 202 and 150 & (Yan et al. 2016) \\
\hline $\begin{array}{l}\text { EDTA functionalized magnetic CS } \\
\text { and GO }\end{array}$ & $\begin{array}{l}\mathrm{Pb} \text { (II), } \\
\mathrm{Cu} \text { (II) } \\
\mathrm{As} \text { (III) }\end{array}$ & $\begin{array}{l}\mathrm{Pb}(\mathrm{II}): 206.52 \\
\mathrm{Cu}(\mathrm{II}): 207.26 \\
\mathrm{As} \text { (III): } 42.75\end{array}$ & (Shahzad et al. 2017b) \\
\hline Phosphorylated CS and GO & $\mathrm{U}(\mathrm{VI})$ & 779.44 & (Cai et al. 2017) \\
\hline GO-CS aerogel & $\mathrm{U}(\mathrm{VI})$ & 250 & (Huang et al. 2017) \\
\hline $\mathrm{CS}$ and GO & $\mathrm{Cr}(\mathrm{VI})$ & 104.16 & (Samuel et al. 2018) \\
\hline Magnetic CS and GO & $\mathrm{Cu}(\mathrm{II})$ & 217.4 & $\begin{array}{l}\text { (Hosseinzadeh and } \\
\text { Ramin 2018) }\end{array}$ \\
\hline Low molecular CS & $\mathrm{Cu}(\mathrm{II})$ & 80 & (Boamah et al. 2016) \\
\hline Cross-linked CS and GO & $\mathrm{Pb}(\mathrm{II})$ & 566 & (Sharma et al. 2019) \\
\hline $\mathrm{CS}$ and GO & $\mathrm{Cr}(\mathrm{VI})$ & 178 & (Moghaddam et al. 2019) \\
\hline Grafted CS and GO & $\mathrm{Cr}(\mathrm{VI})$ & 270.27 & (Samuel et al. 2019) \\
\hline GO-CS-PVA hydrogel & $\begin{array}{l}\mathrm{Cd}(\mathrm{II}) \\
\mathrm{Ni}(\mathrm{II})\end{array}$ & $\begin{array}{l}\mathrm{Cd}(\mathrm{II}): 172 \\
\mathrm{Ni}(\mathrm{II}): 70\end{array}$ & (Li et al. 2019) \\
\hline Magnetic CS and GO & As (III) & 45 & (Sherlala et al. 2019) \\
\hline Magnetic CS and GO & $\mathrm{Ni}(\mathrm{II})$ & 12.24 & (Tran et al. 2019) \\
\hline GO-CS sponge & $\begin{array}{l}\mathrm{Co} \text { (II) } \\
\mathrm{Ni} \text { (II) }\end{array}$ & $\begin{array}{l}\text { Co (II): } 224.8 \\
\mathrm{Ni}(\mathrm{II}): 423.7\end{array}$ & (Di et al. 2019) \\
\hline Membranes using CS-GO & $\mathrm{Pb}(\mathrm{II})$ & 767 & (Croitoru et al. 2020) \\
\hline GO-CS Gadolinium composite & $\mathrm{As}(\mathrm{V})$ & 252 & (Choi et al. 2020) \\
\hline CS and GO & $\begin{array}{l}\mathrm{Cd}(\mathrm{VI}) \\
\mathrm{Cu}(\mathrm{II}) \\
\mathrm{Pb}(\mathrm{II})\end{array}$ & $\begin{array}{l}\mathrm{Cd}(\mathrm{VI}): 48.7 \\
\mathrm{Cu}(\mathrm{II}): 60.7 \\
\mathrm{~Pb}(\mathrm{II}): 32.3\end{array}$ & (Li et al. 2020) \\
\hline $\begin{array}{l}\text { Modified CS with 3-(p-anisyl)-4- } \\
\text { formylsydnone and GO }\end{array}$ & $\begin{array}{l}\mathrm{Cr}(\mathrm{VI}) \\
\mathrm{Cu}(\mathrm{II})\end{array}$ & $\begin{array}{l}\mathrm{Cr}(\mathrm{VI}): 142.85 \\
\mathrm{Cu}(\mathrm{II}): 111.11\end{array}$ & (Anush et al. 2020) \\
\hline GO-Gadolinium composite & $\mathrm{As}(\mathrm{V})$ & 216 & (Lingamdinne et al. 2021) \\
\hline GO-CS- $\mathrm{Fe}_{3} \mathrm{O}_{4}$ & $\mathrm{Cd}(\mathrm{II})$ & 84 & (Parastar et al. 2021) \\
\hline
\end{tabular}


Bessa et al. (2020) reported Hg (II) removal efficiency (97\%) from ultra-pure water with a small mercury dose using CS-GO composite. Simultaneously, using the tap water, river, and seawater, removal efficiency was reduced to about $81 \%, 13 \%$, and $7 \%$, respectively. Their study concluded that chlorine in an aqueous medium significantly reduced the removal efficiency of the composite due to the formation of steady chloromercury complexes. CS-GO nanocomposite could adsorb Pd(II) and $\mathrm{Au}(\mathrm{III})$. CS with 5 wt.\% GO combination showed maximum adsorption 1077 (mg/g) for $\mathrm{Au}(\mathrm{III})$ and 216.9 (mg/g) for Pd(II) (Liu et al. 2012). Other studies highlighted hydrogel's potential obtained using CS-GO and polyvinyl alcohol (PVA) in various proportions, with the optimum being 1:2:4. Adsorption studies showed that the model followed Langmuir isotherm. Co-CSPVA matrix showed the maximum adsorption capacity for $\mathrm{Cd}$ (II) and $\mathrm{Ni}$ (II) as about 172 and $70 \mathrm{mg} / \mathrm{g}$, respectively, for the contact time of $16 \mathrm{~h}$ (Li et al. 2019). GO was mixed with 4-aminothiophenol and $\mathrm{NaNO}_{2}$ to form GO-SH material, mixed with chitosan powder to obtain GO-CS-SH composite material. In multi-metal effluent, the material was found to be most suitable for adsorption of $\mathrm{Cd}(\mathrm{II})$, followed by $\mathrm{Cu}$ (II) and $\mathrm{Pb}$ (II) (Li et al. 2015). Similarly, studies on Go-Cs composite material without any functionalization resulted in the maximum adsorption capacity for $\mathrm{Cu}(\mathrm{II}), \mathrm{Pb}(\mathrm{II})$, and $\mathrm{Cd}(\mathrm{II})$ as about 60,48 , and 32 $\mathrm{mg} / \mathrm{g}$, respectively (Li et al. 2020). Menazea et al. (2020) studied the interactions of heavy metals with CS-GO and proposed a model using density functional theory and suggested that high heavy metal removal can be achieved by CS-GO combination.

\section{Removal of dye}

The textile and printing industry produces dye-containing effluent, which should be treated before discharge into water bodies. Approximately 1 to $15 \%$ of the dye is released into waste water during the dying process, eventually entering the ecosystem (Galindo 2001). Aromatic compounds in paints make their biodegradation an arduous task. Coloured substances in water inhibit the permeation of light and hinder the photosynthesis process. If ingested, these dyes can cause eye burns, nausea, vomiting, dyspnea, and cyanosis disease (Senthilkumaar et al. 2005).

Similar to the removal of metals, adsorption is the method of choice for dye removal. When used individually, $\mathrm{CS}$ and $\mathrm{GO}$ have shown a high affinity for the adsorption of dyes present in the wastewater (Chandel et al. 2020). However, composite formed using chitosan and graphene showed improved adsorption properties over several cycles of repeated usage. Table 4 depicts the various CS-GO composites like hydrogel, beads, spheres, and sponge investigated for dye removal from aqueous solution. However, the adsorption of methylene blue dye on GO adsorbent used alone was $287 \mathrm{mg} / \mathrm{g}$. CS-GO composite material leads to adsorption capacity as high as $402.6 \mathrm{mg} / \mathrm{g}$ (Sabzevari et al. 2018a). Due to the unique properties of CS-GO, they can be used for the adsorption of methylene blue dye. A sponge prepared using chitosan (9\%) with GO exhibited an adsorption capacity of $275.5 \mathrm{mg} / \mathrm{g}$ for methylene blue during a filtration process (Qi et al. 2018b).

Due to the better removal ability of magnetic nanoparticles from an aqueous medium, synthesis and kinetic studies of magnetic nanoparticles for water treatment have been successfully reported. Tran et al. (2017b) demonstrated the enhanced adsorption efficiency of magnetically modified CS-GO composite. The studies reported the adsorption efficiency of $10 \%$ weight of $\mathrm{GO}$ in $\mathrm{CS} / \mathrm{Fe}_{3} \mathrm{O}_{4} / \mathrm{GO}$ nanocomposite for $\mathrm{MB}$ dye after $95 \mathrm{~h}$ for five repeated operation cycles. Neves et al. (2020) prepared a magnetic CS-GO composite to remove basic brown four dye. 
Table 4. CS-GO Nanocomposites for Dye Removal

\begin{tabular}{|c|c|c|c|}
\hline Adsorbent & Dye & Adsorption Capacity (mg/g) & Reference \\
\hline CSGO10 & MB & 74 & (Singh et al. 2019) \\
\hline CS-GO & Reactive black 5 & 277 & (Travlou et al. 2013a) \\
\hline Chitosan/graphene oxide 10 & $M B$, Eosin $Y$ & $\begin{array}{l}\text { MB: } 300 \\
\text { Eosin Y: } 302\end{array}$ & (Chen et al. 2013) \\
\hline GO-CS/silica & CR & 294.12 & (Du et al. 2014) \\
\hline GO was cross-linked with CS & $\begin{array}{l}\text { Acid yellow } 36 \text { and } \\
\text { Acid blue } 74\end{array}$ & $\begin{array}{l}\text { Acid yellow } 36: 68 \\
\text { Acid blue } 74: 85\end{array}$ & (Banerjee et al. 2017) \\
\hline Magnetic GO-CS composite & $\mathrm{MO}$ & 30 & (Tran et al. 2017a) \\
\hline CS-GO sphere & $\mathrm{MO}$ and $\mathrm{Acid}$ red 1 & $\begin{array}{l}\text { MO: } 230.91 \\
\text { Acid red 1:132.94 }\end{array}$ & (Zhang et al. 2018) \\
\hline GO-CS sponge & MB & 275.5 & (Qi et al. 2018a) \\
\hline GO and CS-GO composite & MB & $\begin{array}{l}\text { GO composite: } 287 \\
\text { CS-GO composite: } 402\end{array}$ & (Sabzevari et al. 2018b) \\
\hline Polyacrylate CS-GO hydrogel & MB and Food yellow 3 & $\begin{array}{l}\text { MB } 296 \\
\text { Food yellow 3: } 280.3\end{array}$ & Chang et al. (2020) \\
\hline $\begin{array}{l}\text { Cs reinforced } \\
\text { (CS@GO-Hap) matrix }\end{array}$ & CR, Acid Red 1 and Reactive Red 2 & $\begin{array}{l}\text { CR: } 43.06 \\
\text { Acid Red } 1: 41.32 \\
\text { Reactive Red } 2: 40.03\end{array}$ & Sirajudheen et al. (2020) \\
\hline
\end{tabular}


Composite graphene oxide functionalized using quaternary ammonium salt and magnetic chitosan provided the maximum adsorption capacity of $650(\mathrm{mg} / \mathrm{g})$ and 95(\%). The study showed that in three successive adsorption and desorption cycles, the dye uptake efficiency was $64 \%$. Graphene nanoplates, a graphene derivative crosslinked with chitosan to form composite spheres, were explored for the adsorption of methyl orange and acid red one dye. The high adsorption capacity for methyl orange and acid red 1 was 230.9 (mg/g) and $132.9(\mathrm{mg} / \mathrm{g})$, respectively, which showed the CS-GO sphere's potential as an efficient dye adsorbent. The adsorption capacity was maintained at $90 \%$ after five repeated usage cycles (Zhang et al. 2018). CS-GO bead adsorbent prepared by gel and GO and investigated by researchers for adsorption of various cationic and anionic dyes. For orange dye II, $84(\%)$ removal efficiency was observed with CS/Gel0.1GN.

Vo et al. (2020) prepared hydrogel materials in which chitosan chains crosslinks GO-nanosheets. GO and CS were mixed in solution in the above hybrid, followed by sonification to form hydrogel of GO-CS. While the higher GO level was beneficial for cationic dye's adsorption, higher chitosan hydrogel showed selectivity towards anionic dyes. The combination provides maximum loading of congo red dye about $176(\mathrm{mg} / \mathrm{g})$ (Kamal et al. 2016). Recently, biopolymer-based aerogels have been studied for application in adsorption and water purification processes. Chitosan-based aerogel has emerged as a potential material for the remediation of dye-contaminated water. Chitosan with active amine and hydroxyl groups has a strong tendency to bind with various types of dyes. Chitosan is a highly porous material that has limited application due to its high propensity to collapse. Besides acting as a good filler in the chitosan matrix, graphene oxide provides mechanical strength and enhances chitosan's adsorption efficiency. Aerogel formed using nanocomposite CS-GO aerogels exhibited high retention ability for Indigo Carmine and MB, as 377 and 169 (mg/g), respectively (Luna et al. 2019). Similarly, aerogel prepared using CS-GO was an effective adsorbent for Metanil Yellow dye with removal efficiencies between 91 and 96 (\%). This dye's adsorption capacity was 431.0 $(\mathrm{mg} / \mathrm{g})$ at the adsorbent dose of $8 \mathrm{mg}$, concentration $400(\mathrm{mg} / \mathrm{L})$, for the contact time of about $35 \mathrm{~min}$, maintained at a shaking speed of $175 \mathrm{rpm}$. The aerogel performed the adsorption and desorption up to 5 cycles, which resulted in an adsorption capacity of around 80 (\%) (Lai et al. 2019). Qi et al. (2018b) synthesized GO-CS nanocomposite to remove $\mathrm{MB}$ in column study. Optimum loading for CS into GO solution was $9 \%$ in CSGO hydrogel, which MB released efficiently.

\section{Removal of organic and inorganic pollutants}

Chitosan offers excellent potential for the removal of a variety of contaminants from effluents. Modified and unmodified chitosan-based nanocomposites have shown an effective adsorption potential to eliminate a variety of heavy metals, which include $\mathrm{Cu}$ (II) (Boamah et al. 2016; Modrzejewska et al. 2016), Pb(II) (Shahzad et al. 2017; Dinh et al. 2018), Cr(VI) (Moghaddam et al. 2019; Samuel et al. 2019; Naicker et al. 2020), As(V) (Shahzad et al. 2017a), Ni(II) (Di et al. 2019; Tran et al. 2019), and Hg(II) (Kyzas et al. 2014). Also CS used has been used for removal of inorganic nutrients $\left(\mathrm{NO}^{3-}, \mathrm{NO}^{2-}\right.$, and $\mathrm{PO}_{4}{ }^{-3}$ ) (Jozwiak et al. 2017, 2019; Kumar et al. 2019) and organic pollutants (Jozwiak et al. 2017; Escudero-Oñate and Martínez-Francés 2018). Further, Table 5 summarizes CS composites that have been used to remove organic and inorganic contaminants from wastewater. 
Table 5. Inorganic and Organic Contaminant Removal using CS

\begin{tabular}{|c|c|c|c|}
\hline Pollutant & Adsorbent & $\begin{array}{l}\text { Removal } \\
\text { efficiency (\%) }\end{array}$ & Reference \\
\hline n-hexadecane & $\begin{array}{l}\text { Spores of Bacillus subtilis LAMI008 were } \\
\text { entrapped in } 3 \mathrm{~mm} \text { chitosan } \\
\text { beads and cross-linked with } 0.3 \% \\
\text { glutaraldehyde }\end{array}$ & 100 & $\begin{array}{l}\text { Sar and Rosenberg } \\
\text { (1983) }\end{array}$ \\
\hline Nitrate & $\begin{array}{l}\text { Protonated cross-linked chitosan gel beads } \\
\text { by glutaraldehyde }\end{array}$ & 77 & Jaafari et al. (2001) \\
\hline Hydrocarbons & R. corynebacteriorides immobilized on CS & 60 & Gentili et al. (2006) \\
\hline Fluoride & Chitosan loaded with titanium & 89 & Jagtap et al. (2009) \\
\hline Diheptyl phthalate & Molybdate-impregnated chitosan beads & 92.5 & Barreto et al. (2010) \\
\hline Insecticide (permethrin) & Modified CS with ZnO & 99 & Arayne et al. (2011) \\
\hline $\begin{array}{l}\text { Pesticide } \\
\text { (Atrazine) }\end{array}$ & Cross-linked chitosan-silver nanoparticles & 98 & Saifuddin et al. (2011) \\
\hline Oil & $\begin{array}{l}\text { CS microspheres produced by ionic gelation of } \\
\text { CS with sodium tripolyphosphate }\end{array}$ & 90 & Grem et al. (2013) \\
\hline Hexadecane & $\begin{array}{l}\text { Bacterial strain B. pumilus } \\
\text { entrapped in chitosan }\end{array}$ & 81.83 & Costa et al. (2014) \\
\hline Naphthalene & $\begin{array}{l}\text { Carbon nanotubes mixed with CS/polyvinyl } \\
\text { alcohol and cross-linked with silane }\end{array}$ & 97 & Bibi et al. (2015) \\
\hline Oil & Zirconium-chitosan composites & 79 & $\begin{array}{l}\text { Elanchezhiyan et al. } \\
\text { (2016) }\end{array}$ \\
\hline Hydrocarbons & Chitosan beads & 99 & Dellagnezze et al. (2016) \\
\hline Oil & $\begin{array}{l}\text { chitosan/magnesium-aluminum layered double } \\
\text { hydroxide hybrid composite }\end{array}$ & 78 & $\begin{array}{l}\text { Elanchezhiyan and } \\
\text { Meenakshi (2017) }\end{array}$ \\
\hline Oil & $\begin{array}{l}\text { Superhydrophobic and } \\
\text { superoleophilic chitosan sponge }\end{array}$ & 99 & Su et al. (2017) \\
\hline Fluoride & $\mathrm{Zr}(\mathrm{IV})$ modified CS-GO & 90 & Zhang et al. (2017) \\
\hline Oil & $\begin{array}{l}\text { Amphiphilic sodium salt } \\
\text { of oleoyl carboxymethyl chitosan }\end{array}$ & $75-85$ & Doshi et al. (2018) \\
\hline Naphthanol & Magnetic Cs-Go composite & 99.8 & Rebekah et al. (2020) \\
\hline Ofloxacin & CS-GO & 99 & Suri et al. (2021) \\
\hline
\end{tabular}

Khandegar et al. (2021). "Chitosan nanocomposites," BioResources 16(4), 8525-8566. 8546 
Arayne and co-workers (2011) investigated the potential of raw and $\mathrm{ZnO}$-modified $\mathrm{CS}$ beads to remove insecticide used for agriculture. They found that chitosan beads have outstanding adsorption and removed $49 \%$ and $99 \%$ of an insecticide (permethrin) when using raw and modified chitosan beads, respectively.

Danalioglu et al. (2017) prepared a novel magnetic activated carbon/chitosan composite to remove ciprofloxacin, erythromycin, and amoxicillin. They found the best fit with a Langmuir isotherm model, indicating that $90(\mathrm{mg} / \mathrm{g})$ ciprofloxacin, $178.6(\mathrm{mg} / \mathrm{g})$ erythromycin, and $526.3(\mathrm{mg} / \mathrm{g})$ amoxicillin had adsorbed. Danalioglu et al. (2017) compared the adsorption potential of magnetic CS with activated carbon for ciprofloxacin with alginate- $\mathrm{Fe}_{3} \mathrm{O}_{4}$ hydrogel fibre and $\mathrm{GO}-\mathrm{Ca}$ alginate adsorbent. About $154 \mu \mathrm{g} / \mathrm{g}$ ciprofloxacin was adsorbed using magnetic alginate- $\mathrm{Fe}_{3} \mathrm{O}_{4}$ hydrogel fibre and 18.45 to $39.06 \mathrm{mg} / \mathrm{g}$ GO-Ca alginate adsorbent (Wu et al. 2013).

Saifuddin et al. (2011) removed pesticide (atrazine) using CS-Ag NPs. Maximum 98\% atrazine (from 1 ppm solution) was removed from solution using a composite dosage of $2.0 \mathrm{~g} / \mathrm{L}$ of Cs-Ag NPs. Other investigators have reported using chitosan beads modified with sodium alginate and calcium chloride to remove phenol and o-chlorophenol (Li et al. 2009a). They said that modification in CS enhanced its stability and its sorption capacity toward pollutants. The maximum sorption capacities of $108.7(\mathrm{mg} / \mathrm{g})$ and $97.1(\mathrm{mg} / \mathrm{g})$ were achieved for o-chlorophenol and phenol, respectively. $\mathrm{Zr}(\mathrm{IV})$ is oxyphilic and makes a bond with oxygen present in GO. Researchers have prepared zirconium-chitosan/graphene oxide membrane ( $80 \mu \mathrm{m}$ thick) and evaluated its adsorption capacity for anions present in wastewater. $\mathrm{Zr}(\mathrm{IV})$ forms an electro-positive ion. It has a strong affinity for fluoride ions with more than $90 \%$ removal efficiency in the contact time of around $30 \mathrm{~min}$. The membrane displayed high selectivity for bicarbonate and sulfate ions as well. The membrane with sufficient mechanical strength has been reported to have a high potential for water purification application (Zhang et al. 2017).

CS has been recognized as one of the most effective biopolymers for removing oil droplets from water. CS exhibits a unique assembly that is prone to natural functionalization and permits the modification of novel sportive materials with oilenhanced selectivity and adsorption potential (Farzana and Meenakshi 2015; Elanchezhiyan et al. 2016). Nitrogen, phosphorus and potassium are the vital nutrients required for proper plant growth, but excessive fertilizers in the fields lead to leaching soil and water bodies. As per the World Health Organization, the limit $\mathrm{NO}^{3-}$ and $\mathrm{PO}_{4}^{3-}$ in drinking water is 40 and less than $0.5 \mathrm{mg} / \mathrm{L}$, respectively. The excessive amounts of these components in drinking water are harmful and lead to various diseases such as methemoglobinemia and gastric cancer (Zheng and Wang 2010). Various researchers have explored chitosan composite for nutrient removal from water. Hybrid beads encapsulating chitosan on the graphene oxide functionalized using triaminotriazine have been used to remove nutrients from agricultural soil. These beads were tested on a non-aqueous medium enriched with nutrients such as $\mathrm{NO}^{3-}$ and $\mathrm{PO}_{4}{ }^{3-}$. The retention capacity of beads for $\mathrm{NO}^{3-}$ and $\mathrm{PO}_{4}{ }^{3}$ was 58.5 and $61.4 \mathrm{mg} / \mathrm{g}$, respectively, which was much higher than any of these individual adsorbents (Kumar et al. 2019). In agriculture, pesticides are commonly used to control insects and pests that cause severe damage to the crop. The associated toxic effects of chemical pesticides have prompted researchers to look for biopesticides as an alternative. However, biopesticides' hydrophobicity is the most significant limiting factor in their wide range of applications (Lao et al. 2010). The organic solvents used in high quantities to improve their solubility in an aqueous medium are known to be highly polluting in nature (Muda et al. 2020). Researchers are looking for eco-friendly water 
solubilizing carrier agents to stabilize biopesticides in an aqueous medium chemically. The binding mechanisms for carrier agents include encapsulation, entrapment, adsorption, and ligands (Meredith et al. 2016).

Strontium-90 is found mainly in nuclear waste. Its longer half-life, as well as its biocompatibility, make it toxic for human health. Among numerous methods to treat nuclear waste, adsorption is considered an effective technique to remove strontium. The low adsorption capacity of existing adsorbents such as clay and synthetic hydroxyapatite prompted researchers to develop adsorbents with higher selectivity. It has been found that the maximum adsorption capacity of strontium on GO and chitosan was $146,112 \mathrm{mg} / \mathrm{g}$, respectively. However, its adsorption capacity for GO-chitosan composite was $180 \mathrm{mg} / \mathrm{g}$ (Rouby et al. 2018). Rotenone (1,2,12,12a-tetrahydro-8,9-dimethoxy-2-(1-methylethenyl)-1-benzopyrano(3,5-b)furo(2,3-h)benzopyran-6(6h)-one) is a non-toxic organic pesticide for pests such as corn borers, apple and pea aphids, Mexican bean beetles, and household pests. Researchers have performed studies to improve the hydrophobicity of rotenone using a Cs-GO nano-composite using various $\mathrm{Cs}$ and $\mathrm{GO}$ proportions. The process parameters were optimized, resulting in 48.5 times higher dissolution of pesticide in Cs-GO nanocomposite than control (Muda et al. 2020). The effluent of the dye industry, as well as the pharmaceutical industry, contains 2-naphthol. The studies have shown the potential of magnetically modified Cs-GO composite for its adsorption. The maximum adsorption capacity was $169 \mathrm{mg} / \mathrm{g}$ with almost complete removal efficiency for the treatment time of 45 mins (Rebekah et al. 2020).

\section{CHALLENGES AND FUTURE DIRECTIONS}

CS and GO are natural materials that have shown excellent biomedical and adsorption capacity, which are further improved by combining the two materials. CS-GO, prepared as a nanocomposite, offers a large specific surface area and good electrical properties. These composites promise a bright future for many treatments, including cancer and tumour treatment. The enhanced therapeutic value of CS-GO composite materials has been evaluated using animal model-based studies. They are safe, efficient, and ensure drug delivery at specific locations in the body in a controlled manner. Although advancement has been achieved in in-vivo studies, much work lies in clinical level investigations. The ongoing research on CS-GO is not sufficient and must be enhanced. The analysis described in this review is still in its infancy. It is being continuously improvised, but stringent validation needs to be performed in vivo and in-vitro, followed by assessing long-term adverse effects through extensive clinical trials to obtain an efficient, viable, and safe product. Clinical trials can precisely identify and compare the environmentally most favorable options for many medicinal applications. More clinical data is required to understand the relative advantages and limitations of CS-GO composites compared to CS or GO used alone.

The mounting number of metals, dyes, and organic pollutants can lead to severe environmental degradation. The effect of the same on human health and the eco-system can be disastrous if not addressed soon. CS-GO-based hydrogel, aerogel, beads, and spheres have helped remove metals including $\mathrm{Cu}, \mathrm{Cr}, \mathrm{Pb}, \mathrm{Pd}, \mathrm{As}, \mathrm{Au}$, and $\mathrm{Hg}$, which are otherwise severely toxic. Currently, the research work is focused on the treatment of individual metals or dyes. However, the waste material in the field is a mixture of various metals. Thus, there is an urgent need to study the efficiency of these composite materials 
to treat multi-metal waste. Magnetically modified composite emerged as a potential adsorbent for metals, dyes, organic, and inorganic contaminants. Under laboratory conditions, complete removal of pollutants has been achieved in a few studies. The retention capacity of these composite was found to be closer to $95 \%$. Scale-up studies of these composite can lead to commercial application. Furthermore, the reusability study must also be prioritized in future research to verify the effectiveness and successfully fabricated nanocomposites compared to conventional treatments.

\section{CONCLUDING COMMENTS}

This review has summarized the properties of chitosan (CS), graphene oxide (GO), and CS-GO materials. The application of chitosan and graphene oxide nanocomposite has been studied in the present review, especially its adsorption capability and antimicrobial activity. This unique category of chitosan-based products can be modified with various functional groups to control their hydrophobicity, as well as cationic and anionic properties. The literature that was surveyed in this work makes it clear that the chitosan is a low-cost biopolymer, environmental-friendly, and abundant in availability. However, the modified form of CS-GO has many applications and is cost-effective. Their unique attributes have allowed researchers to use them as a suitable medium to treat many diseases. Although the successful clinical translation of CS-GO composite has not been achieved yet, they have shown great promise, thereby providing hope for new treatment of various decreases soon. In the current scenario, the costs associated with synthesis of CS-GO may not be lowered than other commercially available nanocomposites; therefore, more wellorganized and cost-effective ways are required to produce CS-GO. Future research could examine a low-cost CS-GO composite production technique without compromising environmental and health implications.

\section{REFERENCES CITED}

Aam, B. B., Heggset, E. B., Norberg, A. L., Sørlie, M., Vårum, K. M., and Eijsink, V. G. H. (2010). "Production of chitooligosaccharides and their potential applications in medicine," Marine Drugs 8(5), 1482-1517. DOI: 10.3390/md8051482

Abdou, E. S., Nagy, K. S. A., and Elsabee, M. Z. (2008). "Extraction and characterization of chitin and chitosan from local sources," Bioresource Technology 99(5), 13591367. DOI: 10.1016/j.biortech.2007.01.051

Ahmad, M., Manzoor, K., and Ikram, S. (2017). "Versatile nature of hetero-chitosan based derivatives as biodegradable adsorbent for heavy metal ions. A review," International Journal of Biological Macromolecules 105, 190-203. DOI: 10.1016/j.ijbiomac.2017.07.008

Ali, A., and Ahmed, S. (2018). "A review on chitosan and its nanocomposites in drug delivery," International Journal of Biological Macromolecules 109, 273-286. DOI: 10.1016/j.ijbiomac.2017.12.078

Altundogan, H. S. (2005). "Cr(VI) removal from aqueous solution by iron (III) hydroxide-loaded sugar beet pulp," 40, 1443-1452. DOI:

10.1016/j.procbio.2004.06.027

Alves, N. M., and Mano, J. F. (2008). "Chitosan derivatives obtained by chemical 
modifications for biomedical and environmental applications," International Journal of Biological Macromolecules 43(5), 401-414. DOI: 10.1016/j.ijbiomac.2008.09.007

Anirudhan, T. S., Chithra Sekhar, V., and Athira, V. S. (2020). "Graphene oxide based functionalized chitosan polyelectrolyte nanocomposite for targeted and $\mathrm{pH}$ responsive drug delivery," International Journal of Biological Macromolecules 150, 468-479. DOI: 10.1016/j.ijbiomac.2020.02.053

Anush, S. M., Chandan, H. R., Gayathri, B. H., Asma, Manju, N., Vishalakshi, B., and Kalluraya, B. (2020). "Graphene oxide functionalized chitosan-magnetite nanocomposite for removal of $\mathrm{Cu}(\mathrm{II})$ and $\mathrm{Cr}(\mathrm{VI})$ from waste water," International Journal of Biological Macromolecules 164, 4391-4402. DOI:

10.1016/j.ijbiomac.2020.09.059

Aranaz, I., Mengibar, M., Harris, R., Panos, I., Miralles, B., Acosta, N., Galed, G., and Heras, A. (2009). "Functional characterization of chitin and chitosan," Current Chemical Biology 3(2), 203-230. DOI: 10.2174/187231309788166415

Arayne, M. S., Sultana, N., and Hussain, F. (2011). "Validated RP-HPLC method for determination of permethrin in bulk and topical preparations using UV-vis detector," Journal of Chromatographic Science 49(4), 287-291. DOI: 10.1093/chrsci/49.4.287

Ashrafizadeh, M., Ahmadi, Z., Mohamadi, N., Zarrabi, A., Abasi, S., Dehghannoudeh, G., Tamaddondoust, R. N., Khanbabaei, H., Mohammadinejad, H., and Thakur, V. K. (2020). "Chitosan-based advanced materials for docetaxel and paclitaxel delivery: Recent advances and future directions in cancer theranostics," International Journal of Biological Macromolecules 145, 282-300.

Ates, B., Koytepe, S., Ulu, A., Gurses, C., and Thakur, V. K. (2020). "Chemistry, structures, and advanced applications of nanocomposites from biorenewable resources," Chemical Reviews 120 (17), 9304-9362.

Badry, M. D., Wahba, M. A., Khaled, R., Ali, M. M., and Farghali, A. A. (2017). "Synthesis, characterization, and in vitro anticancer evaluation of iron oxide/chitosan nanocomposites," Inorganic and Nano-Metal Chemistry 47(3), 405-411. DOI: 10.1080/15533174.2016.1186064

Banerjee, P., Barman, S. R., Mukhopadhayay, A., and Das, P. (2017). "Ultrasound assisted mixed azo dye adsorption by chitosan-graphene oxide nanocomposite," Chemical Engineering Research and Design 117, 43-56. DOI: 10.1016/j.cherd.2016.10.009

Bao, H., Pan, Y., Ping, Y., Sahoo, N. G., Wu, T., Li, L., Li, J., and Gan, L. H. (2011). "Chitosan-functionalized graphene oxide as a nanocarrier for drug and gene delivery," Small 7(11), 1569-1578. DOI: 10.1002/smll.201100191

Barreto, R. V. G., Hissa, D. C., Paes, F. A., Grangeiro, T. B., Nascimento, R. F., Rebelo, L. M., Craveiro, A. A., and Melo, V. M. M. (2010). "New approach for petroleum hydrocarbon degradation using bacterial spores entrapped in chitosan beads," Bioresource Technology 101(7), 2121-2125. DOI: 10.1016/j.biortech.2009.11.004

Bastiaens, L., Soetemans, L., D’Hondt, E., and Elst, K. (2019). "Sources of chitin and chitosan and their isolation," Chitin and Chitosan 2019, 1-34. DOI: 10.1002/9781119450467.ch1

Bessa, A., Gonçalves, G., Henriques, B., Domingues, E. M., Pereira, E., and Marques, P. A. A. P. (2020). "Green graphene-chitosan sorbent materials for mercury water remediation," Nanomaterials 10(8), 1474. DOI:10.3390/nano10081474

Bibi, S., Yasin, T., Hassan, S., Riaz, M., and Nawaz, M. (2015). "Chitosan/CNTs green nanocomposite membrane: Synthesis, swelling and polyaromatic hydrocarbons 
removal," Materials Science and Engineering: C, 46, 359-365. DOI:

10.1016/j.msec.2014.10.057

Boamah, P. O., Huang, Y., Hua, M., Onumah, J., Sam-Amoah, L. K., Boamah, P. O., Qian, Y., and Zhang, Q. (2016). "Sorption of copper onto low molecular weight chitosan derivative from aqueous solution," Ecotoxicology and Environmental Safety 129, 154-163. DOI: 10.1016/j.ecoenv.2016.01.014

Bolat, Y., Bilgin, C., Sengül, Günlü, A., Izci, L., Koca, S. B., Çetinkaya, S., Koca, H. U., and others. (2010). "Chitin-chitosan yield of freshwater crab (Potamon potamios Olivier 1804) shell," Pakistan Veterinary Journal, Faculty of Veterinary Science, University of Agriculture, 30(4), 227-231.

Brigham, C. (2017). "Chitin and chitosan: Sustainable, medically relevant biomaterials," International Journal of Biotechnology for Wellness Industries, 6(2), 41-47. DOI: 10.6000/1927-3037.2017.06.02.1

Brine, C. J., and Austin, P. R. (1981). "Chitin variability with species and method of preparation," Comparative Biochemistry and Physiology Part B: Comparative Biochemistry 69(2), 283-286. DOI: 10.1016/0305-0491(81)90242-X

Cai, Y., Wu, C., Liu, Z., Zhang, L., Chen, L., Wang, J., Wang, X., Yang, S., and Wang, S. (2017). "Fabrication of a phosphorylated graphene oxide-chitosan composite for highly effective and selective capture of U(VI)," Environmental Science: Nano 4(9), 1876-1886. DOI: 10.1039/c7en00412e

Casadidio, C., Peregrina, D. V., Gigliobianco, M. R., Deng, S., Censi, R., and Di Martino, P. (2019). "Chitin and chitosans: Characteristics, eco-friendly processes, and applications in cosmetic science," Marine Drugs 17(6). DOI: 10.3390/md17060369

Chang, Z., Chen, Y., Tang, S., Yang, J., Chen, Y., Chen, S., Li, P., and Yang, Z. (2020). "Construction of chitosan / polyacrylate / graphene oxide composite physical hydrogel by semi-dissolution / acidification / sol-gel transition method and its simultaneous cationic and anionic dye adsorption properties," Carbohydrate Polymers 229(October 2019), 115431. DOI: 10.1016/j.carbpol.2019.115431

Chauhan, C., Kaur, P. J., Pant, K. K., and Nigam, K. D. P. (2020). Sustainable Metal Extraction from Waste, Wiley-VCH Publisher, the United States.

Chen, Y., Chen, L., Bai, H., and Li, L. (2013). "Graphene oxide-chitosan composite hydrogels as broad-spectrum adsorbents for water purification," Journal of Materials Chemistry A 1(6), 1992-2001. DOI: 10.1039/c2ta00406b.

Chen, S., Wang, H., Jian, Z., Fei, G., Qian, W., Luo, G., Wang, Z., and Xia, H. (2020). "Novel poly(vinyl alcohol)/chitosan/modified graphene oxide biocomposite for wound dressing application," Macromolecular Bioscience 20, article no. 1900385.

Cheung, R., Ng, T., Wong, J., and Chan, W. (2015). "Chitosan: An update on potential biomedical and pharmaceutical applications," Marine Drugs 13(8), 5156-5186. DOI: $10.3390 / \mathrm{md} 13085156$

Choi, J. S., Lingamdinne, L. P., Yang, J. K., Chang, Y. Y., and Koduru, J. R. (2020). "Fabrication of chitosan/graphene oxide-gadolinium nanorods as a novel nanocomposite for arsenic removal from aqueous solutions," Journal of Molecular Liquids 320, artcle no. 114410. DOI: 10.1016/j.molliq.2020.114410

Costa, S. P., Angelim, A. L., Sousa, M. de F. V. de Q., and Melo, V. M. M. (2014). "Vegetative cells of Bacillus pumilus entrapped in chitosan beads as a product for hydrocarbon biodegradation," International Biodeterioration \& Biodegradation 87, 122-127. DOI: 10.1016/j.ibiod.2013.11.011

Crini, G. (2019). "Historical review on chitin and chitosan biopolymers," Environmental 
Chemistry Letters 17(4), 1623-1643. DOI: 10.1007/s10311-019-00901-0

Croitoru, A., Ficai, A., Ficai, D., Trusca, R., Dolete, G., Andronescu, E., and Turculet, S. C. (2020). "Chitosan / graphene oxide nanocomposite water purification," Materials $13,1-13$.

Danalığlu, S. T., Bayazit, Ş. S., Kerkez Kuyumcu, Ö., and Salam, M. A. (2017). "Efficient removal of antibiotics by a novel magnetic adsorbent: Magnetic activated carbon/chitosan (MACC) nanocomposite," Journal of Molecular Liquids 240, 589596. DOI: 10.1016/j.molliq.2017.05.131

Debnath, S., Maity, A., and Pillay, K. (2014). "Magnetic chitosan-GO nanocomposite: Synthesis, characterization and batch adsorber design for $\mathrm{Cr}(\mathrm{VI})$ removal," $J$. Environ. Chem. Eng. 2, 963-973.

Dellagnezze, B. M., Vasconcellos, S. P., Angelim, A. L., Melo, V. M. M., Santisi, S., Cappello, S., and Oliveira, V. M. (2016). "Bioaugmentation strategy employing a microbial consortium immobilized in chitosan beads for oil degradation in mesocosm scale," Marine Pollution Bulletin 107(1), 107-117. DOI:

10.1016/j.marpolbul.2016.04.011

Dhillon, G. S., Kaur, S., Brar, S. K., and Verma, M. (2013). "Green synthesis approach: Extraction of chitosan from fungus mycelia," Critical Reviews in Biotechnology. DOI: 10.3109/07388551.2012.717217

Di, Z., Ning, L. I., Shuai, C. A. O., Xi, L. I. U., Mingwu, Q., and Pingan, Z. (2019). “A layered chitosan / graphene oxide sponge as reusable adsorbent for removal of heavy metal ions," Chem. Res. Chinese Universities 35(2015), 463-470. DOI: 10.1007/s40242-019-8369-1

Dinh, V.-P., Le, N.-C., Tuyen, L. A., Hung, N. Q., Nguyen, V.-D., and Nguyen, N.-T. (2018). "Insight into adsorption mechanism of lead(II) from aqueous solution by chitosan loaded $\mathrm{MnO}_{2}$ nanoparticles," Materials Chemistry and Physics 207, 294302. DOI: 10.1016/j.matchemphys.2017.12.071

Doshi, B., Repo, E., Heiskanen, J. P., Sirviö, J. A., and Sillanpää, M. (2018). “Sodium salt of oleoyl carboxymethyl chitosan: A sustainable adsorbent in the oil spill treatment," Journal of Cleaner Production 170, 339-350. DOI: 10.1016/j.jclepro.2017.09.163

Du, Q., Sun, J., Li, Y., Yang, X., Wang, X., Wang, Z., and Xia, L. (2014). "Highly enhanced adsorption of congo red onto graphene oxide/chitosan fibers by wetchemical etching of silica nanoparticles," Chemical Engineering Journal, 245, 99106.

Dutta, P. K., Duta, J., and Tripathi, V. S. (2004). "Chitin and chitosan: Chemistry, properties and applications," Journal of Scientific and Industrial Research 63(1), 2031.

Edgar, J. Y. C., and Wang, H. (2017). "Introduction for design of nanoparticle based drug delivery systems," Current Pharmaceutical Design 23(14). DOI: 10.2174/1381612822666161025154003

Elanchezhiyan, S. S., and Meenakshi, S. (2017). "Synthesis and characterization of chitosan/Mg-Al layered double hydroxide composite for the removal of oil particles from oil-in-water emulsion," International Journal of Biological Macromolecules 104, 1586-1595. DOI: 10.1016/j.ijbiomac.2017.01.095

Elanchezhiyan, S. S., Sivasurian, N., and Meenakshi, S. (2016). "Enhancement of oil recovery using zirconium-chitosan hybrid composite by adsorptive method," Carbohydrate Polymers 145, 103-113. DOI: 10.1016/j.carbpol.2016.02.038 
Escudero-Oñate, C., and Martínez-Francés, E. (2018). "A review of chitosan-based materials for the removal of organic pollution from water and bioaugmentation," in: Chitin-Chitosan - Myriad Functionalities in Science and Technology, InTech. DOI: 10.5772/intechopen.76540

Fadlaoui, S., El Asri, O., Mohammed, L., Sihame, A., Omari, A., and Melhaoui, M. (2019). "Isolation and characterization of chitin from shells of the freshwater crab potamon algeriense," Progress on Chemistry and Application of Chitin and its Derivatives 24, 23-35. DOI: 10.15259/PCACD.24.002

Fan, L., Luo, C., Li, X., Lu, F., Qiu, H., and Sun, M. (2012a). "Fabrication of novel magnetic chitosan grafted with graphene oxide to enhance adsorption properties for methyl blue," Journal of Hazardous Materials 215-216, 272-279. DOI: 10.1016/j.jhazmat.2012.02.068

Fan, L., Luo, C., Sun, M., Li, X., Lu, F., and Qiu, H. (2012b). "Preparation of novel magnetic chitosan/graphene oxide composite as effective adsorbents toward methylene blue," Bioresource Technology 114, 703-706. DOI: 10.1016/j.biortech.2012.02.067

Fan, L., Luo, C., Sun, M., Li, X., and Qiu, H. (2013). "Highly selective adsorption of lead ions by water-dispersible magnetic chitosan/graphene oxide composites," Colloids and Surfaces B: Biointerfaces 103, 523-529. DOI: 10.1016/j.colsurfb.2012.11.006

de Faria, A. F., Perreault, F., Shaulsky, E., Arias Chavez, L. H., and Elimelech, M. (2015). "Antimicrobial electrospun biopolymer nanofiber mats functionalized with graphene oxide-silver nanocomposites," ACS Applied Materials \& Interfaces 7(23), 12751-12759. DOI: 10.1021/acsami.5b01639

Farzana, M. H., and Meenakshi, S. (2015). "Exploitation of zinc oxide impregnated chitosan beads for the photocatalytic decolorization of an azo dye," International Journal of Biological Macromolecules 72, 900-910. DOI: 10.1016/j.ijbiomac.2014.09.038

Figueiredo, L., Moura, C., Pinto, L. F. V., Ferreira, F. C., and Rodrigues, A. (2015). "Processing and characterization of 3D dense chitosan pieces, for orthopedic applications, by adding plasticizers," Procedia Engineering 110, 175-182. DOI: 10.1016/j.proeng.2015.06.182

Galindo, C. (2001). "Photooxidation of the phenylazonaphthol AO20 on $\mathrm{TiO}_{2}$ : Kinetic and mechanistic investigations," 45, 997-1005.

Ge, H., and Ma, Z. (2015). "Microwave preparation of triethylenetetramine modified graphene oxide/chitosan composite for adsorption of $\mathrm{Cr}(\mathrm{VI})$," Carbohydrate Polymers 131, 280-287. DOI: 10.1016/j.carbpol.2015.06.025

Geim, A. K. (2009). “Graphene: Status and prospects,” Science 324(5934), 1530-1534. DOI: $10.1126 /$ science. 1158877

Gentili, A. R., Cubitto, M. A., Ferrero, M., and Rodriguéz, M. S. (2006). "Bioremediation of crude oil polluted seawater by a hydrocarbon-degrading bacterial strain immobilized on chitin and chitosan flakes," International Biodeterioration \& Biodegradation 57(4), 222-228. DOI: 10.1016/j.ibiod.2006.02.009

Gómez-Núñez, M. F., Castillo-López, M., Sevilla-Castillo, F., Roque-Reyes, O. J., Romero-Lechuga, F., Medina-Santos, D. I., Martínez-Daniel, R., and Peón, A. N. (2020). "Nanoparticle-based devices in the control of antibiotic resistant bacteria," Frontiers in Microbiology, 11. DOI: 10.3389/fmicb.2020.563821

Grem, I. C. da S., Lima, B. N. B., Carneiro, W. F., Queirós, Y. G. de C., and Mansur, C. R. E. (2013). "Chitosan microspheres applied for removal of oil from produced water 
in the oil industry," Polímeros Ciência e Tecnologia, 23(6), 705-711. DOI: 10.4322/polimeros.2014.008

Guria, M. K., Majumdar, M., and Bhattacharyya, M. (2016). "Green synthesis of protein capped nano-gold particle: An excellent recyclable nano-catalyst for the reduction of nitro-aromatic pollutants at higher concentration," Journal of Molecular Liquids 222, 549-557. DOI: 10.1016/j.molliq.2016.07.087

Hackman, R. (1954). "Studies on chitin I. Enzymic degradation of chitin and chitin esters," Australian Journal of Biological Sciences 7(2), 168. DOI: 10.1071/BI9540168

Hahn, T., Roth, A., Ji, R., Schmitt, E., and Zibek, S. (2020a). "Chitosan production with larval exoskeletons derived from the insect protein production," Journal of Biotechnology 310, 62-67. DOI: 10.1016/j.jbiotec.2019.12.015

Hahn, T., Tafi, E., Paul, A., Salvia, R., Falabella, P., and Zibek, S. (2020b). "Current state of chitin purification and chitosan production from insects," Journal of Chemical Technology \& Biotechnology 95(11), 2775-2795. DOI: 10.1002/jctb.6533

Hajji, S., Younes, I., Ghorbel-Bellaaj, O., Hajji, R., Rinaudo, M., Nasri, M., and Jellouli, K. (2014). "Structural differences between chitin and chitosan extracted from three different marine sources," International Journal of Biological Macromolecules 65, 298-306. DOI: 10.1016/j.ijbiomac.2014.01.045

He, Q. Y., Zhang, N. N., and Wang, X. D. (2011). "Adsorption of graphene oxide / chitosan porous materials for metal ions," Chinese Chemical Letters 22(7), 859-862. DOI: $10.1016 /$ j.cclet.2010.12.049

Hofmann, A. (1979). "How LSD originated," Journal of Psychedelic Drugs 11(1-2), 5360. DOI: 10.1080/02791072.1979.10472092

Hosseini, S. M., Mazinani, S., Abdouss, M., Kalhor, H., Kalantari, K., Amiri, I. S., and Ramezani, Z. (2021). "Designing chitosan nanoparticles embedded into graphene oxide as a drug delivery system," Polymer Bulletin, article no. 0123456789. DOI: $10.1007 / \mathrm{s} 00289-020-03506-8$

Hosseinzadeh, H., and Ramin, S. (2018). "Effective removal of copper from aqueous solutions by modified magnetic chitosan/graphene oxide nanocomposites," International Journal of Biological Macromolecules 113, 859-868. DOI: 10.1016/j.ijbiomac.2018.03.028

Huang, Z., Li, Z., Zheng, L., Zhou, L., Chai, Z., Wang, X., and Shi, W. (2017). "Interaction mechanism of uranium(VI) with three-dimensional graphene oxidechitosan composite: Insights from batch experiments, IR, XPS, and EXAFS spectroscopy," Chemical Engineering Journal 328(Vi), 1066-1074. DOI: 10.1016/j.cej.2017.07.067

Ibitoye, E. B., Lokman, I. H., Hezmee, M. N. M., Goh, Y. M., Zuki, A. B. Z., and Jimoh, A. A. (2018). "Extraction and physicochemical characterization of chitin and chitosan isolated from house cricket," Biomedical Materials 13(2), 25009. DOI: 10.1088/1748-605x/aa9dde

Isa, M. T., Ameh, A. O., Gabriel, J. O., and Adama, K. K. (2012). "Extraction and characterization of chitin from Nigerian sources," Leonardo Electronic Journal of Practices and Technologies 11(21), 73-81.

Ishihara, M., Fujita, M., Kishimoto, S., Hattori, H., and Kanatani, Y. (2012). "Biological, chemical, and physical compatibility of chitosan and biopharmaceuticals," ChitosanBased Systems for Biopharmaceuticals: Delivery, Targeting and Polymer Therapeutics 2012, 93-106. DOI: 10.1002/9781119962977.ch6 
Jaafari, K., Elmaleh, S., Coma, J., and Benkhouja, K. (2001). "Equilibrium and kinetics of nitrate removal by protonated cross-linked chitosan," Water SA, 27(1), 9-13. DOI: 10.4314/wsa.v27i1.5003

Jagtap, S., Thakre, D., Wanjari, S., Kamble, S., Labhsetwar, N., and Rayalu, S. (2009). "New modified chitosan-based adsorbent for defluoridation of water," Journal of Colloid and Interface Science 332(2), 280-290. DOI: 10.1016/j.jcis.2008.11.080

Jain, K. K. (2020). “An overview of drug delivery systems," in: Methods in Molecular Biology. New York, NY: Springer, 1-54. DOI: 10.1007/978-1-4939-9798-5_1

Jaros, K., Kamiński, Wł., Albińska, J., and Nowak, U. (2005). "Removal of heavy metal ions: Copper, zinc and chromium from water on chitosan beads," Environment Protection Engineering 31(3-4), 153-162.

Jia, X., Ahmad, I., Yang, R., and Wang, C. (2017). "Versatile graphene-based photothermal nanocomposites for effectively capturing and killing bacteria, and for destroying bacterial biofilms," Journal of Materials Chemistry B, 5(13), 2459-2467. DOI: 10.1039/C6TB03084J

Jiang, T., James, R., Kumbar, S. G., and Laurencin, C. T. (2014). "Chitosan as a biomaterial," in: Natural and Synthetic Biomedical Polymers 91-113. DOI: 10.1016/B978-0-12-396983-5.00005-3

Jiang, Y., Gong, J. L., Zeng, G. M., Ou, X. M., Chang, Y. N., Deng, C. H., Zhang, J., Liu, H. Y., and Huang, S. Y. (2016). "Magnetic chitosan-graphene oxide composite for anti-microbial and dye removal applications," International Journal of Biological Macromolecules 82, 702-710. DOI: 10.1016/j.ijbiomac.2015.11.021

Jozwiak, T., Filipkowska, U., Szymczyk, P., Kuczajowska-Zadrożna, M., and Mielcarek, A. (2017). "The use of cross-linked chitosan beads for nutrients (nitrate and orthophosphate) removal from a mixture of $\mathrm{P}_{-} \mathrm{PO}_{4}, \mathrm{~N}-\mathrm{NO}_{2}$ and $\mathrm{N}-\mathrm{NO}_{3}$," International Journal of Biological Macromolecules 104, 1280-1293. DOI: 10.1016/j.ijbiomac.2017.07.011

Jozwiak, T., Filipkowska, U., Szymczyk, P., and Mielcarek, A. (2019). "Sorption of nutrients (orthophosphate, nitrate III and V) in an equimolar mixture of $\mathrm{P}-\mathrm{PO}_{4}, \mathrm{~N}-$ $\mathrm{NO}_{2}$ and $\mathrm{N}-\mathrm{NO}_{3}$ using chitosan," Arabian Journal of Chemistry 12(8), 4104-4117. DOI: 10.1016/j.arabjc.2016.04.008

Kamal, M. A., Bibi, S., Bokhari, S. W., Siddique, A. H., and Yasin, T. (2016). "Synthesis and adsorptive characteristics of novel chitosan/graphene oxide nanocomposite for dye uptake," Reactive and Functional Polymers, Elsevier B.V. DOI: 10.1016/j.reactfunctpolym.2016.11.002

Karki, N., Tiwari, H., Tewari, C., Rana, A., Pandey, N., Basak, S., and Sahoo, N. G. (2020). "Functionalized graphene oxide as a vehicle for targeted drug delivery and bioimaging applications," Journal of Materials Chemistry B 8(36), 8116-8148. DOI: 10.1039/D0TB01149E

Kaur, K., Dattajirao, V., Shrivastava, V., and Bhardwaj, U. (2012). "Isolation and characterization of chitosan-producing bacteria from beaches of Chennai, India," Enzyme Research 2012, 1-6. DOI: 10.1155/2012/421683

Kaur, S., and Dhillon, G. S. (2014). "The versatile biopolymer chitosan: Potential sources, evaluation of extraction methods and applications," Critical Reviews in Microbiology 40(2), 155-175.

Kaur, P. J., Chauhan, G., Kaushik, G., and Hussain, C. M. (2020). "Green techniques for remediation of soil using composting," in: The Handbook of Environmental Remediations: Classic and Modern Techniques, S. Palit and C. M. Hussain (eds.), 
Royal Society of Chemistry, Cambridge, UK, pp. 254-267. DOI:

10.1039/9781788015103-00001

Kaya, M., Baran, T., Erdoğan, S., Menteş, A., Aşan Özüsağlam, M., and Çakmak, Y. S. (2014). "Physicochemical comparison of chitin and chitosan obtained from larvae and adult Colorado potato beetle (Leptinotarsa decemlineata)," Materials Science and Engineering: C 45, 72-81. DOI: 10.1016/j.msec.2014.09.004

Kaya, M., Akata, I., Baran, T., and Mentecs, A. (2015). "Physicochemical properties of chitin and chitosan produced from medicinal fungus (Fomitopsis pinicola)," Food Biophysics 10(2), 162-168.

Keshvardoostchokami, M., Piri, F., Jafarian, V., and Zamani, A. (2020). "Fabrication and antibacterial properties of silver/graphite oxide/chitosan and silver/reduced graphene oxide/chitosan nanocomposites," Graphene-based Composite Materials and Applications 72(12), 4477-4485. DOI: 10.1007/s11837-020-04243-z

Khalil, W. F., El-Sayyad, G. S., El Rouby, W. M. A., Sadek, M. A., Farghali, A. A., and El-Batal, A. I. (2020). "Graphene oxide-based nanocomposites (GO-chitosan and GO-EDTA) for outstanding antimicrobial potential against some Candida species and pathogenic bacteria," International Journal of Biological Macromolecules 164, 13701383. DOI: 10.1016/j.ijbiomac.2020.07.205

Khan, M. U. A., Yaqoob, Z., Ansari, M. N. M., Razak, S. I. A., Raza, M. A., Sajjad, A., Haider, S., and Busra, F. M. (2021). "Chitosan/poly vinyl alcohol/graphene oxide based ph-responsive composite hydrogel films: Drug release, anti-microbial and cell viability studies," Polymers 13(18), 3124. DOI: 10.3390/polym13183124

Khanafari, A., Marandi, R., and Sanati, S. H. (2008). "Recovery of chitin and chitosan from shrimp waste by chemical and microbial methods," Iranian Journal of Environmental Health Science and Engineering (IJEHSE) 5(1), 19-24.

Khayrova, A., Lopatin, S., and Varlamov, V. (2019). "Black soldier fly hermetia illucens as a novel source of chitin and chitosan," International Journal of Sciences 8(04), 8186. DOI: 10.18483/ijSci.2015

Khayrova, A., Lopatin, S., and Varlamov, V. (2020). "Obtaining chitin/chitosan-melanin complexes from black soldier fly Hermetia illucens," IOP Conference Series: Materials Science and Engineering 809, article no. 012020. DOI: 10.1088/1757899X/809/1/012020

Khayrova, A., Lopatin, S., and Varlamov, V. (2021). "Obtaining chitin, chitosan and their melanin complexes from insects," International Journal of Biological Macromolecules 167, 1319-1328. DOI: 10.1016/j.ijbiomac.2020.11.086

Khorrami, M., Younesi, H., Hosseinpour, M., and Najafpour, G. (2012). "Production of chitin and chitosan from shrimp shell in batch culture of Lactobacillus plantarum," Chemical \& Biochemical Engineering Quarterly 26(3), 217-223.

Kim, M.-W., Song, Y.-S., Han, Y. S., Jo, Y. H., Choi, M. H., Park, Y.-K., Kang, S. H., Kim, S.-A., Choi, C., and Jung, W.-J. (2017). "Production of chitin and chitosan from the exoskeleton of adult two-spotted field crickets (Gryllus bimaculatus)," Entomological Research 47(5), 279-285. DOI: 10.1111/1748-5967.12239

Knoor, D. (1983). "Dye binding properties of chitin and chitosan," Journal of Food Science 48(1), 36-37. DOI: 10.1111/j.1365-2621.1983.tb14783.x

Konwar, A., Kalita, S., Kotoky, J., and Chowdhury, D. (2016). "Chitosan-iron oxide coated graphene oxide nanocomposite hydrogel: A robust and soft antimicrobial biofilm," ACS Applied Materials \& Interfaces 8(32), 20625-20634. DOI: 10.1021/acsami.6b07510 
Kostarelos, K., and Novoselov, K. S. (2014). "Exploring the interface of graphene and biology," Science 344(6181), 261-263. DOI: 10.1126/science.1246736

Kou, S. (Gabriel), Peters, L. M., and Mucalo, M. R. (2021). "Chitosan: A review of sources and preparation methods," International Journal of Biological Macromolecules 169, 85-94. DOI: 10.1016/j.ijbiomac.2020.12.005

Kumar, S. K., and Jiang, S. (2016). "Chitosan-functionalized graphene oxide: A novel adsorbent an efficient adsorption of arsenic from aqueous solution," Biochemical Pharmacology 4(2), 1698-1713. DOI: 10.1016/j.jece.2016.02.035

Kumar, I. A., Naushad, M., Ahamad, T., and Viswanathan, N. (2019). "Development of triaminotriazine functionalized graphene oxide capped chitosan porous composite beads for nutrients remediation towards water purification," Science of the Total Environment, article no. 135907. DOI: 10.1016/j.ijbiomac.2020.12.016

Kyzas, G. Z., Travlou, N. A., and Deliyanni, E. A. (2014). "The role of chitosan as nanofiller of graphite oxide for the removal of toxic mercury ions," Colloids and Surfaces B: Biointerfaces 113, 467-476. DOI: 10.1016/j.colsurfb.2013.07.055

Kyzas, G. Z., and Bikiaris, D. N. (2015). "Recent modifications of chitosan for adsorption applications: A critical and systematic review," Marine Drugs 13(1), 312337. DOI: $10.3390 / \mathrm{md} 13010312$

Lai, K. C., Hiew, B. Y. Z., Lee, L. Y., Gan, S., Thangalazhy-Gopakumar, S., Chiu, W. S., and Poi Sim Khiew. (2019). "Ice-templated graphene oxide / chitosan aerogel as an effective adsorbent for sequestration of metanil yellow dye," Bioresource Technology 274(November 2018), 134-144. DOI: 10.1016/j.biortech.2018.11.048

Lao, S. B., Zhang, Z. X., Xu, H. H., and Jiang, G. B. (2010). "Novel amphiphilic chitosan derivatives: Synthesis, characterization and micellar solubilization of rotenone," Carbohydrate Polymers 82(4), 1136-1142. DOI: 10.1016/j.carbpol.2010.06.044

Lei, H., Xie, M., Zhao, Y., Zhang, F., Xu, Y., and Xie, J. (2016). "Chitosan/sodium alginate modificated graphene oxide-based nanocomposite as a carrier for drug delivery," Ceramics International 42(15), 17798-17805. DOI: 10.1016/j.ceramint.2016.08.108

Letourneau, D. R., Deven, J. M., and Manocha, M. S. (1976). "Structure and composition of the cell wall of Choanephora cucurbitarum," Canadian Journal of Microbiology 22(4), 486-494.

Li, J. M., Meng, X. G., Hu, C. W., and Du, J. (2009a). “Adsorption of phenol, pchlorophenol and p-nitrophenol onto functional chitosan," Bioresource Technology 100(3), 1168-1173. DOI: 10.1016/j.biortech.2008.09.015

Li, Y., Gao, B., Wu, T., Wang, B., and Li, X. (2009b). “Adsorption properties of aluminum magnesium mixed hydroxide for the model anionic dye Reactive Brilliant Red K-2BP," Journal of Hazardous Materials 164, 1098-1104. DOI: 10.1016/j.jhazmat.2008.09.009

Li, L., Fan, L., Sun, M., Qiu, H., Li, X., Duan, H., and Luo, C. (2013). “Adsorbent for chromium removal based on graphene oxide functionalized with magnetic cyclodextrin-chitosan," Colloids and Surfaces B: Biointerfaces 107, 76-83. DOI: 10.1016/j.colsurfb.2013.01.074

Li, X., Zhou, H., Wu, W., Wei, S., Xu, Y., and Kuang, Y. (2015). "Studies of heavy metal ion adsorption on chitosan / sulfydryl- functionalized graphene oxide composites," Journal of Colloid and Interface Science 448, 389-397. DOI: 10.1016/j.jcis.2015.02.039

Li, P., Gao, Y., Sun, Z., Chang, D., Gao, G., and Dong, A. (2016). “Synthesis, 
Characterization, and bactericidal evaluation of chitosan/guanidine functionalized graphene oxide composites," Molecules 22(1), 12. DOI: 10.3390/molecules22010012

Li, J., Cai, C., Li, J., Li, J., Li, J., Sun, T., Wang, L., Wu, H., and Yu, G. (2018).

"Chitosan-based nanomaterials for drug delivery," Molecules 23(10), 2661. DOI: 10.3390/molecules23102661

Li, C., Yan, Y., Zhang, Q., Zhang, Z., Huang, L., and Zhang, J. (2019). “Adsorption of $\mathrm{Cd}^{2+}$ and $\mathrm{Ni}^{2+}$ from aqueous single-metal solutions on graphene oxide-chitosanpoly(vinyl alcohol) hydrogels," Langmuir 35, 4481-4490. DOI:

10.1021/acs.langmuir.8b04189

Li, L., Zhao, L., and Tian, Y. (2020). "Preparation of graphene oxide / chitosan complex and its adsorption properties for heavy metal ions," Green Processing and Synthesis 9, 294-303.

Limam, Z., Selmi, S., Sadok, S., and El Abed, A. (2011). "Extraction and characterization of chitin and chitosan from crustacean by-products: Biological and physicochemical properties," African Journal of Biotechnology 10(4), 640-647. DOI: 10.5897/AJB10.209

Lingamdinne, L. P., Lee, S., Choi, J. S., Lebaka, V. R., Durbaka, V. R. P., and Koduru, J. R. (2021). "Potential of the magnetic hollow sphere nanocomposite (graphene oxidegadolinium oxide) for arsenic removal from real field water and antimicrobial applications," Journal of Hazardous Materials, 402(August 2020), article no. 123882. DOI: 10.1016/j.jhazmat.2020.123882

Liu, L., Li, C., Bao, C., Jia, Q., Xiao, P., Liu, X., and Zhang, Q. (2012). "Preparation and characterization of chitosan/graphene oxide composites for the adsorption of $\mathrm{Au}$ (III) and Pd(II)," Talanta 93, 350-357. DOI: 10.1016/j.talanta.2012.02.051

Loma, J. D., Tirado, N., Ascui, F., Levi, M., Vahter, M., Broberg, K., and Gardon, J. (2019). "Elevated arsenic exposure and efficient arsenic metabolism in indigenous women around Lake Poopó Bolivia," Science of the Total Environment 657, 179-186. DOI: 10.1016/j.scitotenv.2018.11.473

Luna, M. S. De, Ascione, C., Santillo, C., Verdolotti, L., Lavorgna, M., Buonocore, G. G., Castaldo, R., Filippone, G., Xia, H., and Ambrosio, L. (2019). "Optimization of dye adsorption capacity and mechanical strength of chitosan aerogels through crosslinking strategy and graphene oxide addition," Carbohydrate Polymers 211, 195-203. DOI: 10.1016/j.carbpol.2019.02.002

Ma, Z., Liu, D., Zhu, Y., Li, Z., Li, Z., Tian, H., and Liu, H. (2016). “Graphene oxide / chitin nanofibril composite foams as column adsorbents for aqueous pollutants," Carbohydrate Polymers 144, 230-237. DOI: 10.1016/j.carbpol.2016.02.057.

Mahmoudi, N., Eslahi, N., Mehdipour, A., Mohammadi, M., Akbari, M., Kuchaksaraei, A.S., and Simchi, A. (2017). "Temporary skin grafts based on hybrid graphene oxidenatural biopolymer nanofibers as effective wound healing substitutes: Pre-clinical and pathological studies in animal models," Journal of Materials Science: Materials in Medicine 28, 73. DOI: 10.1007/s10856-017-5874-y

McCallion, C., Burthem, J., Rees-Unwin, K., Golovanov, A., and Pluen, A. (2016). "Graphene in therapeutics delivery: Problems, solutions and future opportunities," European Journal of Pharmaceutics and Biopharmaceutics 104, 235-250. DOI: 10.1016/j.ejpb.2016.04.015

Menazea, A. A., Ezzat, H. A., Omara, W., Basyouni, O. H., Ibrahim, S. A., Mohamed, A. A., Tawfik, W., and Ibrahim, M. A. (2020). "Chitosan/graphene oxide composite as an effective removal of $\mathrm{Ni}, \mathrm{Cu}, \mathrm{As}, \mathrm{Cd}$ and $\mathrm{Pb}$ from wastewater," Computational and 
Theoretical Chemistry 1189, article no. 112980. DOI: 10.1016/j.comptc.2020.112980

Meredith, A. N., Harper, B., and Harper, S. L. (2016). "The influence of size on the toxicity of an encapsulated pesticide: A comparison of micron- and nano-sized capsules," Environment International 86, 68-74. DOI: 10.1016/j.envint.2015.10.012

Minatel, B. C., Sage, A. P., Anderson, C., Hubaux, R., Marshall, E. A., Lam, W. L., and Martinez, V. D. (2018). "Environmental arsenic exposure: From genetic susceptibility to pathogenesis," Environmental International 112(August 2017), 183-197. DOI: 10.1016/j.envint.2017.12.017

Modrzejewska, Z., Rogacki, G., Sujka, W., and Zarzycki, R. (2016). "Sorption of copper by chitosan hydrogel: Kinetics and equilibrium," Chemical Engineering and Processing - Process Intensification, 109, 104-113. DOI: 10.1016/j.cep.2016.08.014

Moghaddam, A., Ghiamati, E., Ayati, A., and Ganjali, M. R. (2019). “Application of the response surface methodology for optimizing the adsorptive removal of chromate using a magnetic crosslinked chitosan nanocomposite," Journal of Applied Polymer Science 136(8), article no. 47077. DOI: 10.1002/app.47077

Mohammed, M. H., Williams, P. A., and Tverezovskaya, O. (2013). "Extraction of chitin from prawn shells and conversion to low molecular mass chitosan," Food Hydrocolloids 31(2), 166-171. DOI: 10.1016/j.foodhyd.2012.10.021

Mohanasrinivasan, V., Mishra, M., Paliwal, J. S., Singh, S. K., Selvarajan, E., Suganthi, V., and Subathra Devi, C. (2014). "Studies on heavy metal removal efficiency and antibacterial activity of chitosan prepared from shrimp shell waste," 3 Biotech 4(2), 167-175. DOI: 10.1007/s13205-013-0140-6

Mojiri, A., Kazeroon, R.A., and Gholami, A. (2019). "Cross-linked magnetic chitosan/activated biochar for removal of emerging micropollutants from water: Optimization by the artificial neural network," Water 11(3), 551. DOI: 10.3390/w11030551

Moradi, S., Hamedi, H., Tonelli, A.E., and Martin, W. (2021). “Graphene oxide composite films and their biomedical and drug delivery applications: A review," Applied Sciences 11 (17), 7776. DOI: 10.3390/app11177776

Morsy, A. M. (2015). "Adsorptive removal of uranium ions from liquid waste solutions by phosphorylated chitosan," Environmental Technology \& Innovation 4, 299-310. DOI: 10.1016/j.eti.2015.10.002

Muda, M. S., Kamari, A., Bakar, S. A., Yusoff, S. N. M., Fatimah, I., Phillip, E., and Din, S. M. (2020). "Chitosan-graphene oxide nanocomposites as water-solubilising agents for rotenone pesticide," Journal of Molecular Liquids 318, article no. 114066. DOI: 10.1016/j.molliq.2020.114066

Muzzarelli, R. A. A., Jeuniaux, C., and Gooday, G. W. (1986). "Chitin in nature and technology," in: Proceedings of the third International Conference on Chitin and Chitosan, Senigallia, Italy, 21-25

Muzzarelli, R. A. A. (1997). "Some modified chitosan and their niche applications," Chitin Handbook, European Chitin Society: Italy, 47-52.

Naicker, C., Nombona, N., and van Zyl, W. E. (2020). "Fabrication of novel magnetic chitosan/graphene-oxide/metal oxide nanocomposite beads for $\mathrm{Cr}$ (VI) adsorption," Chemical Papers 74(2), 529-541. DOI: 10.1007/s11696-019-00895-7

Najafabadi, H., Irani, M., Rad, L., Haratameh, A., and Haririan, I. (2015). "Removal of $\mathrm{Cu}^{2+}, \mathrm{Pb}^{2+}$ and $\mathrm{Cr}^{6+}$ from aqueous solutions using a chitosan/graphene oxide composite nanofibrous adsorbent," RSC Advances 5(21), 16532-16539. DOI: $10.1039 / \mathrm{c} 5 \mathrm{ra} 01500 \mathrm{f}$ 
Nessa, F., Masum, S., Asaduzzaman, M., and Roy, S. K. (2010). "BCSIR a process for the preparation of chitin and chitosan from prawn shell waste," 45(4), 323-330.

Neves, T. de F., Dalarme, N. B., Silva, P. M. M. da, Landers, R., Picone, C. S. F., and Prediger, P. (2020). "Novel magnetic chitosan / quaternary ammonium salt graphene oxide composite applied to dye removal," Journal of Environmental Chemical Engineering 8(4), article no. 103820. DOI: 10.1016/j.jece.2020.103820

Pădurețu, C.-C., Isopescu, R., Rău, I., Apetroaei, M. R., and Schröder, V. (2019). "Influence of the parameters of chitin deacetylation process on the chitosan obtained from crab shell waste," Korean Journal of Chemical Engineering 36(11), 1890-1899. DOI: $10.1007 / \mathrm{s} 11814-019-0379-7$

Pal, J., Verma, H. O., Munka, V. K., Maurya, S. K., Roy, D., and Kumar, J. (2014). "Biological method of chitin extraction from shrimp waste an eco-friendly low cost technology and its advanced application," International Journal of Fisheries and Aquatic Studies IJFAS 1(6), 104-107.

Palza, H. (2015). "Antimicrobial polymers with metal nanoparticles," International Journal of Molecular Sciences 16(1), 2099-2116. DOI: 10.3390/ijms 16012099

Pan, Q., Lv, Y., Williams, G. R., Tao, L., Yang, H., Li, H., and Zhu, L. (2016). "Lactobionic acid and carboxymethyl chitosan functionalized graphene oxide nanocomposites as targeted anticancer drug delivery systems," Carbohydrate Polymers 151, 812-820. DOI: 10.1016/j.carbpol.2016.06.024

Parastar, M., Sheshmani, S., and Shokrollahzadeh, S. (2021). "Cross-linked chitosan into graphene oxide-iron (III) oxide hydroxide as nano-biosorbent for $\mathrm{Pd}(\mathrm{II})$ and $\mathrm{Cd}(\mathrm{II})$ removal," International Journal of Biological Macromolecules 166, 229-237. DOI: 10.1016/j.ijbiomac.2020.10.160

Patra, J. K., Das, G., Fraceto, L. F., Campos, E. V. R., Rodriguez-Torres, M. del P., Acosta-Torres, L. S., Diaz-Torres, L. A., Grillo, R., Swamy, M. K., Sharma, S., Habtemariam, S., and Shin, H.-S. (2018). "Nano based drug delivery systems: Recent developments and future prospects," Journal of Nanobiotechnology 16(1), 71. DOI: 10.1186/s12951-018-0392-8

Paulino, A. T., Simionato, J. I., Garcia, J. C., and Nozaki, J. (2006). "Characterization of chitosan and chitin produced from silkworm crysalides," Carbohydrate Polymers 64(1), 98-103. DOI: 10.1016/j.carbpol.2005.10.032

Pelgrift, R. Y., and Friedman, A. J. (2013). "Nanotechnology as a therapeutic tool to combat microbial resistance," Advanced Drug Delivery Reviews 65(13-14), 18031815. DOI: $10.1016 /$ j.addr.2013.07.011

Percot, A., Viton, C., and Domard, A. (2003). "Characterization of shrimp shell deproteinization," Biomacromolecules 4(5), 1380-1385. DOI: 10.1021/bm034115h

Philibert, T., Lee, B. H., and Fabien, N. (2017). "Current status and new perspectives on chitin and chitosan as functional biopolymers," Applied Biochemistry and Biotechnology 181(4), 1314-1337. DOI: 10.1007/s12010-016-2286-2

Qi, C., Zhao, L., Lin, Y., and Wu, D. (2018a). "Graphene oxide/chitosan sponge as a novel filtering material for the removal of dye from water," Journal of Colloid and Interface Science 517, 18-27. DOI: 10.1016/j.jcis.2018.01.089

Qi, C., Zhao, L., Lin, Y., and Wu, D. (2018b). "Graphene oxide/chitosan sponge as a novel filtering material for the removal of dye from water," Journal of Colloid and Interface Science 517, 18-27. DOI: 10.1016/j.jcis.2018.01.089

Ramachandran, S., Rajinipriya, M., Soulestin, J., and Nagalakshmaiah, M. (2019). "Recent developments in chitosan-based nanocomposites," in: Bio-based Polymers 
and Nanocomposites 183-215. DOI: 10.1007/978-3-030-05825-8_9

Rana, V. K., Choi, M.-C., Kong, J.-Y., Kim, G. Y., Kim, M. J., Kim, S.-H., Mishra, S., Singh, R. P., and Ha, C.-S. (2011). "Synthesis and drug-delivery behavior of chitosan-functionalized graphene oxide hybrid nanosheets," Macromolecular Materials and Engineering 296(2), 131-140. DOI: 10.1002/mame.201000307

Rasoulzadehzali, M., and Namazi, H. (2018). "Facile preparation of antibacterial chitosan/graphene oxide-Ag bio-nanocomposite hydrogel beads for controlled release of doxorubicin," International Journal of Biological Macromolecules 116, 54-63. DOI: 10.1016/j.ijbiomac.2018.04.140

Rebekah, A., Bharath, G., Naushad, M., Viswanathan, C., and Ponpandian, N. (2020). "Magnetic graphene / chitosan nanocomposite: A promising nano- adsorbent for the removal of 2-naphthol from aqueous solution and their kinetic studies," International Journal of Biological Macromolecules 159, 530-538. DOI:

10.1016/j.ijbiomac.2020.05.113

Rinaudo, M. (2006). "Chitin and chitosan: Properties and applications," Progress in Polymer Science 31(7), 603-632. DOI: 10.1016/j.progpolymsci.2006.06.001

Rouby, W. M. A., Farghali, A. A., Sadek, M. A., and Khalil, W. F. (2018). "Fast removal of $\mathrm{Sr}$ ( II ) from water by graphene oxide and chitosan modified graphene oxide," Journal of Inorganic and Organometallic Polymers and Materials 28, 2336-2349. DOI: $10.1007 / \mathrm{s} 10904-018-0885-9$

Sabzevari, M., Cree, D. E., and Wilson, L. D. (2018a). "Graphene oxide-chitosan composite material for treatment of a model dye effluent," ACS Omega 3(10), 1304513054. DOI: $10.1021 /$ acsomega.8b01871

Sabzevari, M., Cree, D. E., and Wilson, L. D. (2018b). "Graphene oxide-chitosan composite material for treatment of a model dye effluent," ACS Omega 3(10), 1304513054. DOI: $10.1021 /$ acsomega.8b01871

Sagheer, F. A. Al, Al-Sughayer, M. A., Muslim, S., and Elsabee, M. Z. (2009). "Extraction and characterization of chitin and chitosan from marine sources in Arabian Gulf," Carbohydrate Polymers 77(2), 410-419. DOI:

10.1016/j.carbpol.2009.01.032

Saifuddin, N., Nian, C. Y., Zhan, L. W., and Ning, K. X. (2011). "Chitosan-silver nanoparticles composite as point-of-use drinking water filtration system for household to remove pesticides in water," Asian Journal of Biochemistry 6(2), 142 159. DOI: 10.3923/ajb.2011.142.159

Salam, M. A. (2017). "Preparation and characterization of chitin/magnetite/multiwalled carbon nanotubes magnetic nanocomposite for toxic hexavalent chromium removal from solution," Journal of Molecular Liquids 233, 197-202. DOI: 10.1016/j.molliq.2017.03.023

Samuel, M. S., Bhattacharya, J., Raj, S., Santhanam, N., Singh, H., and Singh, N. D. P. (2018). "Efficient removal of chromium(VI) from aqueous solution using chitosan grafted graphene oxide (CS-GO) nanocomposite," International Journal of Biological Macromolecules 121, 285-292. DOI: 10.1016/j.ijbiomac.2018.09.170

Samuel, M. S., Bhattacharya, J., Raj, S., Santhanam, N., Singh, H., and Pradeep Singh, N. D. (2019). "Efficient removal of chromium(VI) from aqueous solution using chitosan grafted graphene oxide (CS-GO) nanocomposite," International Journal of Biological Macromolecules 121(August 2019), 285-292. DOI: 10.1016/j.ijbiomac.2018.09.170

Sar, N., and Rosenberg, E. (1983). "Emulsifier production by Acinetobacter calcoaceticus strains," Current Microbiology 9(6), 309-313. 
Schwarz, S., Mende, M., and Schwarz, D. (2016). "Chitosan - A natural sorbent for copper ions," International Journal of Environmental Pollution and Remediation, 4. DOI: 10.11159/ijepr.2016.003

Senthilkumaar, S., Varadarajan, P. R., Porkodi, K., and Subbhuraam, C. V. (2005). "Adsorption of methylene blue onto jute fiber carbon: kinetics and equilibrium studies," 284, 78-82. DOI: 10.1016/j.jcis.2004.09.027

Shahzad, A., Miran, W., Rasool, K., Nawaz, M., Jang, J., Lim, S.-R., and Lee, D. S. (2017). "Heavy metals removal by EDTA-functionalized chitosan graphene oxide nanocomposites," RSC Advances 7(16), 9764-9771. DOI: 10.1039/C6RA28406J

Sharma, P., Singh, A. K., and Shahi, V. K. (2019). "Selective adsorption of Pb(II) from aqueous medium by cross-linked chitosan-functionalized graphene oxide adsorbent," ACS Sustainable Chemistry \& Engineering 7(1), 1427-1436. DOI: 10.1021/acssuschemeng.8b05138

Sherlala, A. I. A., Raman, A. A. A., Bello, M. M., and Buthiyappan, A. (2019). "Adsorption of arsenic using chitosan magnetic graphene oxide nanocomposite," Journal of Environmental Management 246(May), 547-556. DOI: 10.1016/j.jenvman.2019.05.117

Shi, Y., Xiong, Z., Lu, X., Yan, X., Cai, X., and Xue, W. (2016). "Novel carboxymethyl chitosan-graphene oxide hybrid particles for drug delivery," Journal of Materials Science: Materials in Medicine 27(11), 169. DOI: 10.1007/s10856-016-5774-6

Singh, N., Riyajuddin, S., Ghosh, K., Mehta, S. K., and Dan, A. (2019). "Chitosangraphene oxide hydrogels with embedded magnetic iron oxide nanoparticles for dye removal," ACS Applied Nano Materials 2(11), 7379-7392. DOI: 10.1021/acsanm.9b01909

Sirajudheen, P., Karthikeyan, P., Ramkumar, K., and Meenakshi, S. (2020). "Effective removal of organic pollutants by adsorption onto chitosan supported graphene oxidehydroxyapatite composite: A novel reusable adsorbent," Journal of Molecular Liquids 318, article no. 114200. DOI: 10.1016/j.molliq.2020.114200

Soon, C. Y., Tee, Y. B., Tan, C. H., Rosnita, A. T., and Khalina, A. (2018). "Extraction and physicochemical characterization of chitin and chitosan from Zophobas morio larvae in varying sodium hydroxide concentration," International Journal of Biological Macromolecules 108, 135-142. DOI: 10.1016/j.ijbiomac.2017.11.138

Sponza, D. T., and Alicanoglu, P. (2017). "Reuse and recovery of raw hospital wastewater containing ofloxacin after photocatalytic treatment with nano graphene oxide magnetite," Water Science \& Technology, 1-18. DOI: 10.2166/wst.2017.531

Su, C., Yang, H., Zhao, H., Liu, Y., and Chen, R. (2017). "Recyclable and biodegradable superhydrophobic and superoleophilic chitosan sponge for the effective removal of oily pollutants from water," Chemical Engineering Journal 330, 423-432. DOI: 10.1016/j.cej.2017.07.157

Suri, A. (2020). Exclusion of Pharmaceutical Pollutants by Electrocoagulation and Ultra-Sonication Adsorption Using Chitosan Cross-Link with Graphene Oxide, Master's Thesis, Guru Gobind Singh Indraprastha University, New Delhi, India.

Suri, A., Khandegar, V., and Kaur, P. J. (2020). "Groundwater for sustainable development of loxacin exclusion using novel HRP immobilized chitosan cross-link with graphene-oxide nanocomposite," Groundwater for Sustainable Development 12, article no. 100515. DOI: 10.1016/j.gsd.2020.100515

Suri, A., and Khandegar, V. (2021). "Exclusion of pharmaceutical compounds by UA assisted EC process," Journal of Hazardous, Toxic, and Radioactive Waste 25(2), 
04021004. DOI: 10.1061/(asce)hz.2153-5515.0000598

Tan, Y. N., Lee, P. P., and Chen, W. N. (2020). "Microbial extraction of chitin from seafood waste using sugars derived from fruit waste-stream," AMB Express 10(1). DOI: $10.1186 / \mathrm{s} 13568-020-0954-7$

Tao, R., Wang, C., Zhang, C., Li, W., Zhou, H., Chen, H., and Ye, J. (2019). "Characterization, cytotoxicity and genotoxicity of graphene oxide and folate coupled chitosan nanocomposites loading polyprenol and fullerene based nanoemulsion against MHCC97H Cells," Journal of Biomedical Nanotechnology 15(3), 555-570. DOI: $10.1166 /$ jbn.2019.2698

Tarafdar, A., and Biswas, G. (2013). "Extraction of chitosan from prawn shell wastes and examination of its viable commercial applications," International Journal on Theoretical and Applied Research in Mechanical Engineering 2(3), 2391-3182.

Thakur, V. K., and Thakur, M. K. (2014). "Recent advances in graft copolymerization and applications of chitosan: A review," ACS Sustainable Chemical Engineering 2, 2637-2652. DOI: 10.1021/sc500634p

Thakur, V. K., and Voicu, S. I. (2016). "Recent advances in cellulose and chitosan based membranes for water purification: A concise review," Carbohydrate Polymers 146, 148-165. DOI: 10.1016/j.carbpol.2016.03.030

Tharanathan, R. N., and Kittur, F. S. (2003). "Chitin - The undisputed biomolecule of great potential," Critical Reviews in Food Science and Nutrition 43(1), 61-87. DOI: 10.1080/10408690390826455

Thirunavukkarasu, N., and Shanmugam, A. (2009). "Extraction of chitin and chitosan from mud crab Scylla tranquebarica (Fabricius, 1798)," International Journal on Applied Bio-Engineering 3(2), 31-33. DOI: 10.18000/ijabeg.10048

Tran, H. V, Bui, L. T., Dinh, T. T., Le, D. H., Huynh, C. D., and Trinh, A. X. (2017). "Graphene oxide / $\mathrm{Fe}_{3} \mathrm{O}_{4}$ / chitosan nanocomposite: A recoverable and recyclable adsorbent for organic dyes removal. Application to methylene blue," Materials Research Express 4(3), 035701.

Tran, L. T., Tran, H. V, Le, T. D., Bach, G. L., and Tran, L. D. (2019). "Studying Ni ( II ) adsorption of magnetite / graphene oxide / chitosan nanocomposite," 2019(Ii).

Travlou, N. A., Kyzas, G. Z., Lazaridis, N. K., and Deliyanni, E. A. (2013a). "Graphite oxide/chitosan composite for reactive dye removal," Chemical Engineering Journal 217, 256-265. DOI: 10.1016/j.cej.2012.12.008

Travlou, N. A., Kyzas, G. Z., Lazaridis, N. K., and Deliyanni, E. A. (2013b). "Functionalization of graphite oxide with magnetic chitosan for the preparation of a nanocomposite dye adsorbent," Langmuir 29(5), 1657-1668. DOI: 10.1021/la304696y

Upadhyay, U., Sreedhar, I., Singh, S. A., Patel, C. M., and Anitha, K. L. (2021). "Recent advances in heavy metal removal by chitosan based adsorbents," Carbohydrate Polymers 251(May 2020), article no. 117000. DOI: 10.1016/j.carbpol.2020.117000

Varma, A., Deshpande, S., and Kennedy, J. (2004). "Metal complexation by chitosan and its derivatives: A review," Carbohydrate Polymers 55(1), 77-93. DOI: 10.1016/j.carbpol.2003.08.005

Vassallo, A., Silletti, M. F., Faraone, I., and Milella, L. (2020). 'Nanoparticulate antibiotic systems as antibacterial agents and antibiotic delivery platforms to fight infections," Journal of Nanomaterials 2020, 1-31. DOI: 10.1155/2020/6905631

Vo, T. S., Vo, T. T. B. C., Suk, J. W., and Kim, K. (2020). "Recycling performance of graphene oxide-chitosan hybrid hydrogels for removal of cationic and anionic dyes," 
Nano Convergence 7(1), 4. DOI: 10.1186/s40580-019-0215-0

Wang, N., Wang, S., Shen, T., Cao, Y., Ding, G., Wu, Y., and Du, R. (2013a).

"Chitosan/cellulose microfiltration membranes for endotoxin removal," Advanced Materials Research 781-784, 1007-1010.

DOI: $10.4028 / w w w . s c i e n t i f i c . n e t / A M R .781-784.1007$

Wang, S., Xu, L., Wang, L., Liang, A., and Jiang, Z. (2013b). “A new and simple resonance Rayleigh scattering method for human serum albumin using graphite oxide as probe," Luminescence 28(6), 842-846. DOI: 10.1002/bio.2443

Wang, H., Liu, Y., Zeng, G., Hu, X., Hu, X., Li, T., Li, H., Wang, Y., and Jiang, L. (2014). "Grafting of $\beta$-cyclodextrin to magnetic graphene oxide via ethylenediamine and application for Cr(VI) removal," Carbohydrate Polymers 113, 166-173. DOI: 10.1016/j.carbpol.2014.07.014

Wang, J., Wang, L., Yu, H., Zain-ul-Abdin, Chen, Y., Chen, Q., Zhou, W., Zhang, H., and Chen, X. (2016). "Recent progress on synthesis, property and application of modified chitosan: An overview," International Journal of Biological Macromolecules 88, 333-344. DOI: 10.1016/j.ijbiomac.2016.04.002

Wang, J., and Zhuang, S. (2017). "Removal of various pollutants from water and wastewater by modified chitosan adsorbents," Critical Reviews in Environmental Science and Technology 47(23), 2331-2386. DOI: 10.1080/10643389.2017.1421845

Wang, C., Zhang, Z., Chen, B., Gu, L., Li, Y., and Yu, S. (2018). "Design and evaluation of galactosylated chitosan/graphene oxide nanoparticles as a drug delivery system," Journal of Colloid and Interface Science 516, 332-341. DOI: 10.1016/j.jcis.2018.01.073

Wang, W., Xue, C., and Mao, X. (2020). "Chitosan: Structural modification, biological activity and application," International Journal of Biological Macromolecules 164, 4532-4546. DOI: 10.1016/j.ijbiomac.2020.09.042

WHO. (1997). “Guidelines for Drinking Water Quality, $2^{\text {nd }}$ Edition," in: Surveillance and Control of Community Supplies, World Health Organization, Geneva.

Wu, S., Zhao, X., Li, Y., Zhao, C., Du, Q., Sun, J., Wang, Y., Peng, X., Xia, Y., Wang, Z., and Xia, L. (2013). "Adsorption of ciprofloxacin onto biocomposite fibers of graphene oxide/calcium alginate," Chemical Engineering Journal, 230, 389-395. DOI: 10.1016/j.cej.2013.06.072

Xie, M., Zhang, F., Peng, H., Zhang, Y., Li, Y., Xu, Y., and Xie, J. (2019). “Layer-bylayer modification of magnetic graphene oxide by chitosan and sodium alginate with enhanced dispersibility for targeted drug delivery and photothermal therapy," Colloids and Surfaces B: Biointerfaces 176, 462-470. DOI:

10.1016/j.colsurfb.2019.01.028

Yadav, M., Goswami, P., Paritosh, K., Kumar, M., Pareek, N., and Vivekanand, V. (2019). "Seafood waste: A source for preparation of commercially employable chitin/chitosan materials," Bioresources and Bioprocessing 6(1). DOI: 10.1186/s40643-019-0243-y

Yan, H., Yang, H., Li, A., and Cheng, R. (2016). "pH-tunable surface charge of chitosan/graphene oxide composite adsorbent for efficient removal of multiple pollutants from water," Chem Eng J, 284, 1397-1405.

Yang, H., Bremner, D. H., Tao, L., Li, H., Hu, J., and Zhu, L. (2016). “Carboxymethyl chitosan-mediated synthesis of hyaluronic acid-targeted graphene oxide for cancer drug delivery," Carbohydrate Polymers 135, 72-78. DOI:

10.1016/j.carbpol.2015.08.058 
Yang, C., Yan, Z., Lian, Y., Wang, J., and Zhang, K. (2019). "Graphene oxide coated shell-core structured chitosan/PLLA nanofibrous scaffolds for wound dressing," Journal of Biomaterials Science Polymer Edition 31(12), 1-15. DOI: 10.1080/09205063.2019.1706149

Yassue-Cordeiro, P. H., Severino, P., Souto, E. B., Gomes, E. L., Yoshida, C. M. P., de Moraes, M. A., and da Silva, C. F. (2018). "Chitosan-based nanocomposites for drug delivery," in: Applications of Nanocomposite Materials in Drug Delivery, Elsevier, pp. 1-26. DOI: 10.1016/B978-0-12-813741-3.00001-7

Yilmaz Atay, H. (2019). "Antibacterial activity of chitosan-based systems," in: Functional Chitosan, 457-489. DOI: 10.1007/978-981-15-0263-7_15

Younes, I., and Rinaudo, M. (2015). "Chitin and chitosan preparation from marine sources. structure, properties and applications," Marine Drugs 13(3), 1133-1174. DOI: $10.3390 / \mathrm{md} 13031133$

Yu, X., Trase, I., Ren, M., Duval, K., Guo, X., and Chen, Z. (2016). "Design of nanoparticle-based carriers for targeted drug delivery," Journal of Nanomaterials 2016, 1-15. DOI: 10.1155/2016/1087250

ZabihiSahebi, A., Koushkbaghi, S., Pishnamazi, M., Askari, A., Khosravi, R., and Irani, M. (2019). "Synthesis of cellulose acetate/chitosan/SWCNT/ $/ \mathrm{Fe}_{3} \mathrm{O}_{4} / \mathrm{TiO}_{2}$ composite nanofibers for the removal of $\mathrm{Cr}(\mathrm{VI})$, As(V), Methylene blue and Congo red from aqueous solutions," International Journal of Biological Macromolecules 140, 12961304. DOI: 10.1016/j.ijbiomac.2019.08.214

Zhang, M., Haga, A., Sekiguchi, H., and Hirano, S. (2000). "Structure of insect chitin isolated from beetle larva cuticle and silkworm (Bombyx mori) pupa exuvia," International Journal of Biological Macromolecules 27(1), 99-105. DOI: 10.1016/S0141-8130(99)00123-3

Zhang, L., Luo, H., Liu, P., Fang, W., and Geng, J. (2016). "A novel modified graphene oxide/chitosan composite used as an adsorbent for Cr(VI) in aqueous solutions," International Journal of Biological Macromolecules 87, 586-596. DOI: 10.1016/j.ijbiomac.2016.03.027

Zhang, J., Chen, N., Li, M., and Feng, C. (2017). "Synthesis and environmental application of zirconium - chitosan / graphene oxide membrane," Journal of the Taiwan Institute of Chemical Engineers 77, 106-112. DOI: 10.1016/j.jtice.2017.04.029

Zhang, C., Chen, Z., Guo, W., Zhu, C., and Zou, Y. (2018). "Simple fabrication of chitosan / graphene nanoplates composite spheres for efficient adsorption of acid dyes from aqueous solution," International Journal of Biological Macromolecules 112, 1048-1054. DOI: 10.1016/j.ijbiomac.2018.02.074

Zhang, J., Ding, E., Xu, S., Li, Z., Fakhri, A., and Gupta, V. K. (2020). "Production of metal oxides nanoparticles based on poly-alanine/chitosan/reduced graphene oxide for photocatalysis degradation, anti-pathogenic bacterial and antioxidant studies," International Journal of Biological Macromolecules 164, 1584-1591. DOI: 10.1016/j.ijbiomac.2020.07.291

Zhao, X., Wei, Z., Zhao, Z., Miao, Y., Qiu, Y., Yang, W., Jia, X., Liu, Z., and Hou, H. (2018). "Design and development of graphene oxide nanoparticle/chitosan hybrids showing $\mathrm{pH}$-sensitive surface charge-reversible ability for efficient intracellular doxorubicin delivery," ACS Applied Materials \& Interfaces 10(7), 6608-6617. DOI: 10.1021/acsami.7b16910

Zheng, Y., and Wang, A. (2010). "Nitrate adsorption using poly(dimethyl diallyl 
ammonium chloride)/polyacrylamide hydrogel," Journal of Chemical and Engineering Data 55(9), 3494-3500. DOI: 10.1021/je100169r

Zhou, G., Wang, K. P., Liu, H. W., Wang, L., Xiao, X. F., Dou, D. D., and Fan, Y. B. (2018). "Three-dimensional polylactic acid @ graphene oxide / chitosan sponge bionic filter: Highly ef fi cient adsorption of crystal violet dye," International Journal of Biological Macromolecules, 113, 792-803. DOI: 10.1016/j.ijbiomac.2018.02.017

Article submitted: July 7, 2020; Peer review completed: September 18, 2021; Revised version received and accepted: September 30, 2021; Published: October 7, 2021.

DOI: 10.15376/biores.16.4.Khandegar 